Staff Working Paper/Document de travail du personnel 2020-54

Last updated: December 15, 2020

\title{
Labor Market Policies During an Epidemic
}

by Serdar Birinci, ${ }^{1}$ Fatih Karahan, ${ }^{2}$ Yusuf Mercan ${ }^{3}$ and Kurt See ${ }^{4}$

${ }^{1}$ Federal Reserve Bank of St. Louis

${ }^{2}$ Federal Reserve Bank of New York

${ }^{3}$ Faculty of Business and Economics, University of Melbourne

${ }^{4}$ Canadian Economic Analysis Department

Bank of Canada, Ottawa, Ontario, Canada K1A 0G9

serdar.birinci@stls.frb.org, fatih.karahan@ny.frb.org, yusuf.mercan@unimelb.edu.au,seek@bankofcanada.ca

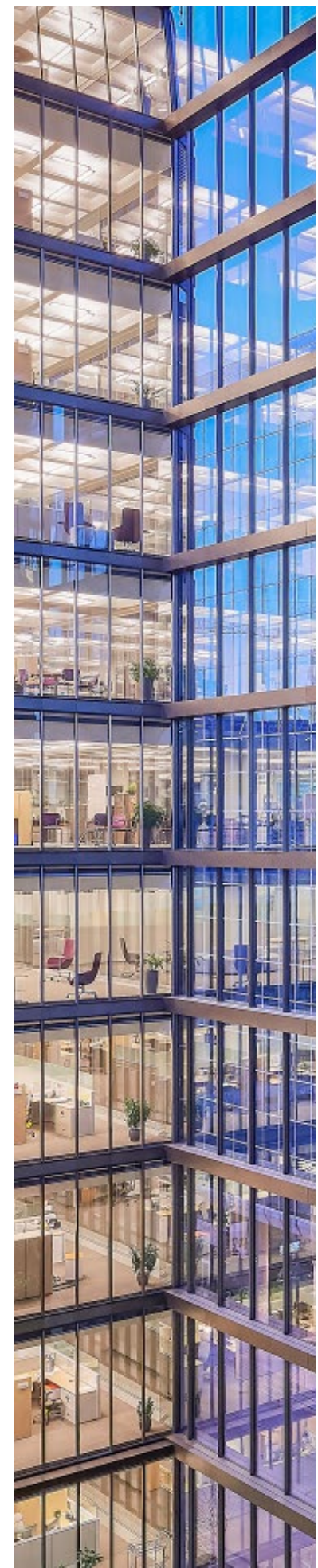

Bank of Canada staff working papers provide a forum for staff to publish work-in-progress research independently from the Bank's Governing Council. This research may support or challenge prevailing policy orthodoxy. Therefore, the views expressed in this paper are solely those of the authors and may differ from official Bank of Canada views. No responsibility for them should be attributed to the Bank. 


\section{Acknowledgements}

We are grateful to Chris Edmond, Lukas Freund, Stan Rabinovich, Benjamin Schoefer, our editor Johannes Spinnewijn, David Wiczer, two anonymous referees, and various seminar participants for their useful comments. The views expressed in this paper are those of the authors and do not necessarily reflect the position of the Federal Reserve Bank of St. Louis, the Federal Reserve Bank of New York, the Federal Reserve System, or the Bank of Canada. 


\section{Abstract}

We study the positive and normative implications of labor market policies that counteract the economic fallout from containment measures during an epidemic. We incorporate a standard epidemiological model into an equilibrium search model of the labor market to compare unemployment insurance (UI) expansions and payroll subsidies. In isolation, payroll subsidies that preserve match capital and enable a swift economic recovery are preferred over a costequivalent UI expansion. When considered jointly, however, a cost-equivalent optimal mix allocates 20 percent of the budget to payroll subsidies and 80 percent to UI. The two policies are complementary, catering to different rungs of the productivity ladder. The relatively small proportion allocated to payroll subsidies is sufficient to preserve high-productivity jobs but this also leaves room for social assistance to workers who face inevitable job losses.

Bank topics: Coronavirus disease (COVID-19); Business fluctuations and cycles; Fiscal policy; Labour markets

JEL codes: E24, E62, J64 


\section{Introduction}

The COVID-19 pandemic has resulted in a rapid contraction of economic activity and a severe deterioration of labor market conditions in the U.S. To mitigate the effects of massive dislocation in the labor market, the U.S. government introduced policy measures through the Coronavirus Aid, Relief, and Economic Security (CARES) Act, whose initial aid package is two trillion dollars. In this paper, we study the two prominent components of this package: the expansion of unemployment insurance (UI) benefits and the introduction of payroll subsidies. We make two broad contributions to the literature. On the positive side, we analyze the differential effects of direct transfers to the unemployed through a UI benefit expansion vis-à-vis granting firms payroll subsidies to preserve matches. Taking these differential effects into account, our normative contribution answers an important question: How should the government allocate limited resources between these programs?

These two policies have distinct goals and labor market effects. The expansion of UI payments provides additional income to the large number of job losers during the pandemic-driven downturn. In comparison, the Payroll Protection Program (PPP), which extends forgivable loans to firms, aims to prevent business closures and keep worker-firm matches intact so that when labor demand rebounds, a swifter recovery follows. A key advantage of this program is that it preserves the match capital that has been formed in the labor market over many years of investment.

We analyze these policies for the period of the pandemic and the subsequent recovery. We combine the classical epidemiological model of Kermack and McKendrick (1927) with an equilibrium search model of the labor market in Section 2. Our model consists of two sectors (essential and nonessential) with ex-ante identical, risk averse, hand-to-mouth households and risk neutral firms. The model has four features that capture the key aspects that are relevant for policy analysis.

First, the infection probability depends on an agent's involvement in production and also on the aggregate labor supply and the population of infected agents. The spread of infection thus depends on (public) containment policies as well as (private) behavioral responses through the supply of labor. This allows us to study how labor market policies interact with containment measures.

Second, financial frictions and wage rigidity lead to inefficient job separations. Some firms are subject to financial frictions in that per-period net profits must remain above a certain threshold. If this constraint binds, then the worker-firm match temporarily dissolves. In addition, the downward wage rigidity implies that infections result in reduced productivity but not lower pay. Hence, the epidemic increases the probability of inefficient separations by reducing the firm surplus.

Third, the labor market features match-specific productivity that grows stochastically over time, capturing the idea that preserving long-tenure jobs is important for aggregate productivity and output. Firms have a recall option when temporary separations occur regardless of payroll protection, which allows us to discipline a policy's contribution to match preservation.

Finally, the government has two sets of policy instruments: a containment policy expressed as a tax on production and fiscal policies in the form of UI benefits and payroll subsidies. Our framework allows us to study these policies' effects in isolation and solve for their optimal mix. Importantly, these policies are distinct because when UI is generous and payroll subsidies are 
absent, the severance of a match is more likely to result in a permanent match dissolution as i) some firms may no longer be operational to even rehire, ii) labor market frictions may hinder rehiring, iii) workers may find new matches and, finally, iv) recall rejection rates may be higher.

We calibrate the model's steady state to match key moments of the U.S. labor market prior to the epidemic (Section 3) and introduce the epidemic as a one-time unanticipated shock through an infection of a small share of the population (Section 4). Concurrently, the government introduces a containment policy. The relationship between match productivity and the financial constraint determines the composition of the job losses that occur in a downturn: If more-productive firms can borrow more, then a larger share of the job destruction occurs for low-wage jobs. We discipline this relationship using micro data on the magnitude and composition of job losses during the epidemic.

We use our model to evaluate the policy options by simulating an increase in UI generosity that is similar to that of the CARES Act and a cost-equivalent payroll subsidy. Implementing a UI expansion in isolation leads to a large rise in unemployment. The lost match capital results in persistently low average labor productivity (ALP) and low post-containment output as the newly formed jobs are low-productivity ones. Payroll subsidies achieve the opposite by preserving existing matches because they allow financially constrained firms that would otherwise engage in layoffs to continue operating. The preservation of match capital softens the decline in employment, productivity and output, and the economy recovers faster. UI provides additional insurance to job losers who fall off the job ladder, whereas payroll subsidies preserve workers' positions along the ladder. However, payroll subsidies also have two drawbacks relative to UI. First, there is no direct insurance benefit to job losers. Second, while subsidies allow some firms to retain their matches while idle, they also enable others to continue active production. The ensuing higher economic activity results in more infections. Comparing a UI expansion to a payroll subsidy in isolation, the former yields a welfare gain of 0.18 percent in additional lifetime consumption, while the latter yields 0.76 percent, implying that a payroll subsidy is preferred over a cost-equivalent UI expansion.

We then proceed to computing the optimal policy mix, subject to the same amount of total government spending. The optimal policy allocates 20 percent of the budget to payroll subsidies and the remaining 80 percent to UI expansion. Although payroll subsidies comprise a smaller share of spending, we show that this partial expenditure achieves most of the gains that can be obtained by allocating the entire budget to payroll subsidies. The initial marginal gains of spending on payroll subsidies are large. Thus, the optimal policy sets the payroll subsidy to an amount that is just enough to preserve high-productivity matches as any payments in excess yield limited marginal gains and, importantly, the optimal policy leaves fiscal space for UI payments. The increased UI generosity provides consumption insurance to workers whose jobs are not saved by payroll subsidies. With more-generous UI payments, the unemployment rate rises more, but the additional decline and slow recovery of output are completely offset through payroll subsidies that preserve highproductivity matches. Thus, the two labor market policies are complementary.

Different countries have implemented lockdowns of varying stringency. We show that the share of the budget allocated to payroll subsidies increases with the strictness of the contain- 
ment measures. A more-aggressive containment policy leads to the permanent dissolution of highproductivity matches that would have survived under more-lax containment, raising the importance of firm preservation and, thereby, the value of payroll subsidies.

Our analysis abstracts away from at least one important margin. The COVID-19 pandemic and the resulting containment policies have a strong sectoral component, with high-contact and nonessential jobs being disproportionately affected. Depending on how long the epidemic lasts and how persistent its effects are, it may be desirable to have some workers move away from sectors that face persistent declines. Payroll subsidies directed toward these sectors are more likely to hinder mobility and unnecessarily delay the reallocation process. The optimal policy for an economy that allows for sectoral allocation may therefore feature an even larger share of funds allocated for UI.

This paper contributes to the emerging literature on the economic effects of the COVID-19 pandemic (see Alvarez et al., 2020; Atkeson, 2020; Berger et al., 2020; Bick and Blandin, 2020; Brotherhood et al., 2020; Ganong et al., 2020; Garriga et al., 2020; Glover et al., 2020; Faria-e Castro, 2020b; Kurmann et al., 2020, among others). Our work is closely related to studies that analyze the labor market effects of the epidemic (see Alon et al., 2020; Boar and Mongey, 2020; Fang et al., 2020; Giupponi and Landais, 2020; Gregory et al., 2020; Kapicka and Rupert, 2020; Mitman and Rabinovich, 2020). Relative to this literature, we jointly study UI and payroll subsidies and analyze their differential effects on the labor market. To the best of our knowledge, this is the first study to analyze the trade-offs between different labor market policies, their optimal mix, and how they interact with the strength of containment measures.

Our work also makes broader contributions to the literature that uses quantitative models to study the labor market effects of UI (Krusell et al., 2010; Nakajima, 2012; Jung and Kuester, 2015; Mitman and Rabinovich, 2015; Kolsrud et al., 2018; Landais et al., 2018; Chodorow-Reich et al., 2019; Hagedorn et al., 2019; Birinci and See, 2020) and payroll subsidies (Burdett and Wright, 1989; Tilly and Niedermayer, 2016; Cooper et al., 2017; Cahuc et al., 2018). First, we present a framework suitable for jointly studying both policies. In the model, financial frictions and rigid wages generate inefficient separations that both policies can mitigate. Crucially, we do not homogenize job separations; instead, we distinguish between idle matches, temporary layoffs with a recall option, and permanent separations to capture the differential effects of UI and payroll subsidies. Second, we identify key complementarities between these two policies. To the best of our knowledge, existing work studies each of these policies in isolation and ignores their interactions.

\section{An Equilibrium Labor Market Model in an Epidemic}

We synthesize a basic epidemiological SIR model with an equilibrium labor search model that features match-specific productivity and job recalls. We then use our model to study labor market policies proposed to lessen the economic impact of the epidemic.

\subsection{The Environment}

Time is discrete and runs forever. The economy is populated by a measure one of workers and a continuum of ex-ante identical firms in two sectors: essential and nonessential. Households in 
each sector are ex-ante identical and there is no mobility across sectors. Here, we describe the nonessential sector in detail and only outline key differences in the essential sector.

Households. Households are risk averse and differ in terms of their employment status, health status $h$, match-specific capital $z$, and wage $w$. A worker can be either employed $W$, unemployed on temporary layoff $U_{T}$, or unemployed and permanently separated $U_{P}$. Employed workers can be attached to firms that are either actively producing or idle, while workers on temporary layoff can be recalled back to their previous employers. Employed households have the option to quit and permanently dissolve the match each period. Unemployed households search for jobs and, upon contact, decide whether to accept an offer. Thus, individuals can reduce their own risk of infection by either quitting a job or refusing a new offer.

In terms of health, households are classified as either susceptible $S$, infected $I$, recovered $R$, or dead $D$. Susceptible workers can become infected by engaging in production or by meeting infected agents for reasons unrelated to economic activity; e.g., meeting an infected neighbor. Similar to Eichenbaum, Rebelo, and Trabandt (2020), we model this infection probability as

$$
e_{n}\left(N^{I}, I\right)=\pi_{1} n N^{I}+\pi_{2} I
$$

where $n \in\{0,1\}$ indicates whether the individual is employed and actively producing; $N^{I}$ is the mass of actively employed infected workers; and $I$ denotes the mass of infected people in the economy. Infected people recover or die at exogenous rates $\pi^{R}$ and $\pi^{D}$, respectively, and the recovered are permanently immune to the disease. These transition probabilities can be summarized by

\begin{tabular}{c|cccc} 
& $S$ & $I$ & $R$ & $D$ \\
\hline$S$ & $1-e_{n}$ & $e_{n}$ & 0 & 0 \\
$\Pi_{n}\left(h, h^{\prime}\right)=$ & 0 & $1-\pi^{R}-\pi^{D}$ & $\pi^{R}$ & $\pi^{D}$ \\
$R$ & 0 & 0 & 1 & 0 \\
$D$ & 0 & 0 & 0 & 1
\end{tabular}

Firms, wages and the labor market. The labor market is characterized by random search. The output from a match is given by $y=\alpha^{h} z$. We assume $\alpha^{I}<\alpha^{S}=\alpha^{R}$; i.e., infection reduces health-specific productivity but recovery fully restores it. Match-specific productivity takes on a discrete set of values, $z \in\left\{z_{0}, \ldots, z_{N_{z}}\right\}$. The productivity of a new match starts at the lowest value $z_{0}$ and increases to the next level with probability $\xi$ as long as the match is actively producing.

Once matched with a worker, firms face three choices every period: i) keep the match active and produce, ii) pause production and become idle, or iii) permanently terminate the match. Active firms produce, pay workers their wage $w$ (discussed below) and incur a fixed operating cost $c_{F}$. Firms that pause production avoid this fixed cost but still fulfill their payroll obligations. ${ }^{1}$ Production is paused when output falls to a level that is unable to offset operating costs, possibly due

\footnotetext{
${ }^{1}$ The decision to pause or resume production is frictionless. Further, workers in idle matches remain on the payroll and do not look for new jobs.
} 
to worker infection or a government-imposed lockdown. ${ }^{2}$ Once a match is permanently terminated, there is no option to recall the worker. Therefore, a firm exercises this option only when the surplus that it captures from the match is negative.

There are two types of firms in the nonessential sector. A $\omega$ share of firms is financially constrained (C) and these firms cannot run a per-period loss larger than a productivity-specific limit $\underline{a}(z) \cdot{ }^{3}$ This dependence on productivity allows us to capture any systematic variation in the amount of borrowing firms can tap into. When the financial constraint binds, the firm is forced to put its worker on temporary layoff. The recall option arrives at exogenous rate $r$, but recalls occur only if both parties agree to resume the match. This recall option may disappear permanently with exogenous probability $\chi_{r}$ each period or when the worker finds another job while on layoff. Other firms are unconstrained $(\mathrm{U})$ and their per-period profits are not subject to any requirements.

In addition to the endogenous separations initiated by the firm or the worker, matches also separate exogenously at rate $\delta$. This type of separation also leads to a temporary layoff with a recall option.

In summary, temporary layoffs occur because of i) binding financial constraints or ii) exogenous separations. Meanwhile, permanent separations occur when i) the firm or worker's match surplus is negative, ii) a worker on temporary layoff finds a new job, or iii) the recall option expires.

Wages are paid as a health-dependent piece rate $\phi \alpha^{h}$ of match productivity $z{ }^{4}$ The piece rate implies that wages rise with productivity. Wages are downward rigid: Becoming infected reduces productivity but does not result in lower pay. The possibility of job dissolution and the loss of match capital implies that infection can result in long-term earnings losses for households.

Taking stock, the model allows for inefficient separations through several margins. First, financial frictions potentially lead to the separations of highly productive matches. While these have a recall option, this option may expire or the worker may start a new job. Second, some exogenous separations eventually lead to permanent separations that are potentially inefficient. Lastly, sticky wages in conjunction with financial frictions cause otherwise perfectly viable matches to separate.

To match with workers, entrants pay a cost $\kappa$ to post a vacancy. Meetings with a worker happen with probability $q(\theta)$, where labor market tightness $\theta=v / u$ is the ratio of the mass of vacancies and unemployed workers. The analogous probability for workers is $f(\theta)=\theta q(\theta)$. Labor markets are segmented; i.e., workers in a given sector can only meet with firms in the same sector.

Government. The government has several policy tools. It can reduce economic interactions through a containment policy in the form of a proportional tax $\tau_{q} \in[0,1]$ on match output in the nonessential sector. It can pay unemployment benefits $b$ to households and provide payroll subsidies

\footnotetext{
${ }^{2}$ Understanding the policy tools to keep firms in business during the ongoing COVID-19 pandemic is an important part of the policy debate. At the same time, because of the link between economic activity and the spread of the virus, saving firms need not come at the cost of more contagion. We model a fixed cost and the decision to "pause" production precisely to allow for this. If the fixed cost is sufficiently high, then firms may be better off remaining idle even if the government covers a large share of their wage bill.

${ }^{3}$ This friction captures the idea that not all firms can access financial markets under the same terms and they may furlough their worker, even if the net present value of the match to the firm is still positive.

${ }^{4}$ The dependence on health captures the fact that the outside option of a worker depends on their health.
} 
to nonessential firms by covering a fraction $\tau_{p} \in[0,1]$ of the wages.

Key differences of the essential sector. Essential firms differ from nonessential firms in three ways. First, essential firms do not have the option to pause production. Second, all essential firms are financially unconstrained. Third, payroll and containment policies do not apply to essential firms, while changes in UI generosity affect both sectors through workers' outside options.

Timing. Each period opens during the production and consumption stages: Matched firms decide whether to operate or pause production; active worker-firm pairs produce; wages are paid to workers; and the unemployed receive UI benefits. Next, health shocks are realized. Then the labor market opens: Recall that options stochastically expire; firms create vacancies; new matches are formed; temporarily laid off workers may be recalled; and exogenous job separations occur. Next, the match productivity of active matches stochastically improves. Finally, matched workers and firms unilaterally decide whether to keep or terminate the match before entering the next period.

\subsection{Household Problem}

$W_{k}^{h}(z, w)$ denotes the value of an employed household with health $h \in\{S, I, R\}$, matched to a firm of type $k \in\{C, U\}$, with productivity $z$ and wage $w .^{5}$ Similarly, $U_{T, k}^{h}(z, w)$ and $U_{P}^{h}$ are the values of unemployed households on temporary and permanent layoff (i.e., with and without a recall option), respectively. $J_{k}^{h}(z, w)$ is the value of a firm that is matched with a worker, $V_{T, k}^{h}(z, w)$ is the value of a vacant firm with a worker on temporary layoff, and $V$ is the value of a new entrant.

In each period, the worker and the firm have the option to permanently dissolve an existing match. Let $d_{W, k}^{h}, d_{J, k}^{h} \in\{0,1\}$ indicate that an existing match yields a positive surplus to the worker and the firm, respectively. The joint outcome is then given by $d_{k}^{h}(z, w)=d_{W, k}^{h}(z, w) \times d_{J, k}^{h}(z, w)$. These indicators solve the following problems:

$$
\begin{aligned}
& d_{W, k}^{h}(z, w)=\arg \max _{d \in\{0,1\}}\left\{d \times W_{k}^{h}(z, w)+(1-d) \times U_{P}^{h}\right\} \\
& d_{J, k}^{h}(z, w)=\arg \max _{d \in\{0,1\}}\left\{d \times J_{k}^{h}(z, w)+(1-d) \times V\right\} .
\end{aligned}
$$

Upon contact, the firms and unemployed workers decide whether to initiate a match. Let $d_{U_{T}, k, k^{\prime}}^{h} \in\{0,1\}$ indicate whether a new match with a firm of type $k^{\prime}$ yields a positive surplus to a worker on temporary layoff from a firm of type $k$ with productivity $z$ and wage $w:^{6}$

$$
d_{U_{T}, k, k^{\prime}}^{h}(z, w)=\arg \max _{d \in\{0,1\}}\left\{d \times W_{k^{\prime}}^{h}\left(z_{0}, w^{h}\right)+(1-d) \times U_{T, k}^{h}(z, w)\right\} .
$$

If the worker declines the offer, then they remain unemployed and keep the recall option from the previous match $U_{T, k}^{h}(z, w)$. Otherwise, they start at the lowest productivity and the wage associated

\footnotetext{
${ }^{5} w$ is a state variable because wage rigidity implies that health status does not pin down wages. For example, an infected worker that started their job prior to infection would be paid the wage of a non-infected worker.

${ }^{6}$ Note that state variables $(z, w)$ in this indicator function refer to the outside option when the new firm is financially unconstrained; i.e., the productivity and wage in the latest job to which the worker might be recalled.
} 
with it. A contact results in a new job if both parties agree: $d_{k, k^{\prime}}^{h}(z, w)=d_{U_{T}, k, k^{\prime}}^{h}(z, w) \times d_{J, k}^{h}\left(z_{0}, w^{h}\right)$.

The value of an employed household working for a firm of type $k \in\{C, U\}$ is given by

$$
\begin{aligned}
W_{k}^{h}(z, w) & =u(w)+\beta \sum_{h^{\prime} \in\{S, I, R\}} \Pi_{l}\left(h, h^{\prime}\right)\left[\delta \mathbb{E}_{z^{\prime} \mid z, l} U_{T, k}^{h^{\prime}}\left(z^{\prime}, \max \left\{w, w^{h^{\prime}}\right\}\right)\right. \\
& \left.+(1-\delta) \mathbb{E}_{z^{\prime} \mid z, l} \widetilde{W}_{k}^{h^{\prime}}\left(z^{\prime}, \max \left\{w, w^{h^{\prime}}\right\}\right)\right],
\end{aligned}
$$

where $l$ refers to the firm's production decision (active or idle). ${ }^{7}$ The max operator captures the downward wage rigidity, which only binds when a susceptible worker becomes infected on the job or during a temporary layoff. Note that wages rise as match capital $z$ improves, but we suppress this dependence for conciseness. The match exogenously dissolves with probability $\delta$, leading to a temporary layoff. If the match survives with the complementary probability, then the worker moves to the endogenous decision stage and obtains the continuation value $\widetilde{W}_{k}^{h^{\prime}}$ given by

$$
\widetilde{W}_{k}^{h}(z, w)=\left(1-\gamma_{k}^{h}(z, w)\right)\left[d_{k}^{h}(z, w) W_{k}^{h}(z, w)+\left(1-d_{k}^{h}(z, w)\right) U_{P}^{h}\right]+\gamma_{k}^{h}(z, w) U_{T, k}^{h}(z, w) .
$$

The indicator $\gamma_{k}^{h} \in\{0,1\}$ denotes whether the financial constraint binds. If it does, then the worker goes on temporary layoff. The constraint is a requirement on the per-period profits given by

$$
\gamma_{C}^{h}(z, w)=\mathbb{I}\left\{\left(1-\tau_{q}\right) \alpha^{h} z-\left(1-\tau_{p}\right) w-c_{F} \leq-\underline{a}(z)\right\} \quad \text { and } \quad \gamma_{U}^{h}(z, w)=0
$$

where $\tau_{q}$ is the containment policy that is modeled as a tax on output and $\tau_{p}$ controls the payroll subsidy provided to firms. Next, the value of a worker on temporary layoff is given by

$$
\begin{aligned}
U_{T, k}^{h}(z, w) & =u(b)+\beta \sum_{h^{\prime} \in\{S, I, R\}} \Pi_{0}\left(h, h^{\prime}\right)\left(1-\chi_{r}\right)\left[f(\theta) \mathbb{E}_{k^{\prime}} \widetilde{W}_{k, k^{\prime}}^{h^{\prime}}(z, w)\right. \\
& \left.+r \widetilde{W}_{k}^{h^{\prime}}\left(z, \max \left\{w, w^{h^{\prime}}\right\}\right)+(1-f(\theta)-r) U_{T, k}^{h^{\prime}}\left(z, \max \left\{w, w^{h^{\prime}}\right\}\right)\right] \\
& +\sum_{h^{\prime} \in\{S, I, R\}} \Pi_{0}\left(h, h^{\prime}\right) \chi_{r}\left[f(\theta) \mathbb{E}_{k^{\prime}} \widetilde{W}_{k^{\prime}}^{h^{\prime}}\left(z_{0}, w^{h^{\prime}}\right)+(1-f(\theta)) U_{P}^{h^{\prime}}\right] .
\end{aligned}
$$

The recall option survives with probability $\left(1-\chi_{r}\right)$, in which case the worker is recalled with probability $r$ and the match maintains its pre-layoff productivity $z$. The worker can receive a new offer with probability $f(\theta)$ from a firm of type $k^{\prime}$. The value of having this offer is given by ${ }^{8}$

$$
\begin{aligned}
\widetilde{W}_{k, k^{\prime}}^{h}(z, w) & =\left(1-\gamma_{k^{\prime}}^{h}\left(z_{0}, w^{h}\right)\right)\left[d_{k, k^{\prime}}^{h}(z, w) W_{k^{\prime}}^{h}\left(z_{0}, w^{h}\right)+\left(1-d_{k, k^{\prime}}^{h}(z, w)\right) U_{T, k}^{h}(z, w)\right] \\
& +\gamma_{k^{\prime}}^{h}\left(z_{0}, w^{h}\right) U_{T, k}^{h}\left(z_{0}, w^{h}\right) .
\end{aligned}
$$

\footnotetext{
${ }^{7}$ The expectation over match productivity $z, \mathbb{E}_{z^{\prime} \mid z, l}$, also depends on the firm's production decision $l$ because if the match pauses, then productivity remains constant.

${ }^{8}$ If the firm is financially unconstrained but the match is not formed, then the worker keeps their recall option from the previous match. Hence, at the end of the first line of Equation (4), we have $U_{T, k}^{h}(z, w)$. We assume that when the financial constraint of the new firm binds, the worker continues with a recall option from the new match. Therefore, in the second line of Equation (4), we have $U_{T, k}^{h}\left(z_{0}, w^{h}\right)$.
} 
The expectation operators in Equation (3) account for the fact that the new firm a worker meets may be financially constrained

$$
\begin{aligned}
\mathbb{E}_{k^{\prime}} \widetilde{W}_{k^{\prime}}^{h^{\prime}}\left(z_{0}, w^{h^{\prime}}\right) & =\omega \widetilde{W}_{C}^{h^{\prime}}\left(z_{0}, w^{h^{\prime}}\right)+(1-\omega) \widetilde{W}_{U}^{h^{\prime}}\left(z_{0}, w^{h^{\prime}}\right) \\
\mathbb{E}_{k^{\prime}} \widetilde{W}_{k, k^{\prime}}^{h^{\prime}}(z, w) & =\omega \widetilde{W}_{k, C}^{h^{\prime}}(z, w)+(1-\omega) \widetilde{W}_{k, U}^{h^{\prime}}(z, w) .
\end{aligned}
$$

Finally, the value of an unemployed household with no recall option is

$$
U_{P}^{h}=u(b)+\beta \sum_{h^{\prime} \in\{S, I, R\}} \Pi_{0}\left(h, h^{\prime}\right)\left[f(\theta) \mathbb{E}_{k^{\prime}} \widetilde{W}_{k^{\prime}}^{h^{\prime}}\left(z_{0}, w^{h^{\prime}}\right)+(1-f(\theta)) U_{P}^{h^{\prime}}\right] .
$$

\subsection{Firm Problem}

The value of a firm of type $k$, productivity $z$, matched with a worker of health $h$ is given by

$$
\begin{aligned}
J_{k}^{h}(z, w) & =\max _{l \in\{0,1\}}\left\{l \times\left[\left(1-\tau_{q}\right) \alpha^{h} z-\left(1-\tau_{p}\right) w-c_{F}\right]+(1-l) \times\left[-\left(1-\tau_{p}\right) w\right]\right\} \\
& +\beta \sum_{h^{\prime} \in\{S, I, R\}} \Pi_{l}\left(h, h^{\prime}\right)\left[\delta \mathbb{E}_{z^{\prime} \mid z, l} V_{T, k}^{h^{\prime}}\left(z^{\prime}, \max \left\{w, w^{h^{\prime}}\right\}\right)\right. \\
& \left.+(1-\delta) \mathbb{E}_{z^{\prime} \mid z, l} \widetilde{J}_{k}^{h^{\prime}}\left(z^{\prime}, \max \left\{w, w^{h^{\prime}}\right\}\right)\right] .
\end{aligned}
$$

The first max operator reflects the firm's production decision. If production pauses $\left(l^{h}(z, w)=0\right)$, the worker's risk of infection is lower, they remain with the firm, and the match productivity remains constant. If the firm decides to produce, it pays the operating cost $c_{F}$ in addition to the wages. Here, the worker's active employment risks additional infection but the match quality stochastically improves. The value of a matched firm at the separation decision stage is

$$
\widetilde{J}_{k}^{h}(z, w)=\left(1-\gamma_{k}^{h}(z, w)\right)\left[d_{k}^{h}(z, w) J_{k}^{h}(z, w)+\left(1-d_{k}^{h}(z, w)\right) V\right]+\gamma_{k}^{h}(z, w) V_{T, k}^{h}(z, w) .
$$

The value of a vacant firm with a furloughed employee is given by

$$
\begin{aligned}
V_{T, k}^{h}(z, w) & =\beta\left(1-\chi_{r}\right) \sum_{h^{\prime} \in\{S, I, R\}} \Pi_{0}\left(h, h^{\prime}\right) \times\left[f ( \theta ) \left[\mathbb{E}_{k^{\prime}}\left(1-\gamma_{k^{\prime}}^{h^{\prime}}\left(z_{0}, w^{h^{\prime}}\right)\right)\right.\right. \\
& {\left.\left[d_{k, k^{\prime}}^{h^{\prime}}(z, w) V+\left(1-d_{k, k^{\prime}}^{h^{\prime}}(z, w)\right) V_{T, k}^{h^{\prime}}\left(z, \max \left\{w, w^{h^{\prime}}\right\}\right)\right]+\gamma_{k^{\prime}}^{h^{\prime}}\left(z_{0}, w^{h^{\prime}}\right) V\right] } \\
& \left.+r \widetilde{J}_{k}^{h^{\prime}}\left(z, \max \left\{w, w^{h^{\prime}}\right\}\right)+(1-f(\theta)-r) V_{T, k}^{h^{\prime}}\left(z, \max \left\{w, w^{h^{\prime}}\right\}\right)\right]+\beta \chi_{r} V .
\end{aligned}
$$

The first term in the second line (in brackets) indicates that when a worker on temporary layoff rejects a new offer, they keep their option to be recalled back to their previous employer, but if they accept a new offer, then the job in the previous employer's firm is left vacant. ${ }^{9}$ The last term

\footnotetext{
${ }^{9}$ Here, $\mathbb{E}_{k^{\prime}}$ is the expectation of whether the firm's financial constraint binds and resembles Equation (5).
} 
in the second line captures the case where the new firm's financial constraint binds; the worker continues with a recall option from the new match.

The value of posting a new vacancy is given by

$$
\begin{aligned}
V & =-\kappa+\beta q(\theta) \frac{1}{u} \sum_{h, h^{\prime} \in\{S, I, R\}} \Pi_{0}\left(h, h^{\prime}\right)\left[\left(u_{P}^{h}+\chi_{r} \sum_{k, z} u_{T, k}^{h}(z)\right) \mathbb{E}_{k^{\prime}} \widetilde{J}_{k^{\prime}}^{h^{\prime}}\left(z_{0}, w^{h^{\prime}}\right)\right. \\
& +\left(1-\chi_{r}\right) \sum_{k, z} u_{T, k}^{h}(z) \mathbb{E}_{k^{\prime}}\left(1-\gamma_{k^{\prime}}^{h^{\prime}}\left(z_{0}, w^{h^{\prime}}\right)\right)\left[d_{k, k^{\prime}}^{h^{\prime}}(z, w) J_{k^{\prime}}^{h^{\prime}}\left(z_{0}, w^{h^{\prime}}\right)\right. \\
& \left.\left.+\left(1-d_{k, k^{\prime}}^{h^{\prime}}(z, w)\right) V\right]+\gamma_{k^{\prime}}^{h^{\prime}}\left(z_{0}, w^{h^{\prime}}\right) V_{T, k^{\prime}}^{h^{\prime}}\left(z_{0}, w^{h^{\prime}}\right)\right]
\end{aligned}
$$

Here, $u_{T, k}^{h}(z)$ and $u_{P}^{h}$ denote the mass of unemployed workers on temporary layoff with a recall option to a job with match capital $z$ and unemployed workers on permanent layoff, respectively, and $u=\sum_{h}\left(u_{P}^{h}+\sum_{k, z} u_{T, k}^{h}(z)\right)$ is the total mass of unemployed. When this firm meets with a worker, its financial type is revealed. If the firm-worker pair decides to keep the match, then it becomes productive in the next period. We assume free entry: an infinite supply of potential new entrants pushes the value of posting a new vacancy to zero, $V=0$.

Appendix A.1 defines a stationary equilibrium and A.2 provides the computational details.

\section{Calibration}

We match several targets of the U.S. economy prior to and during the pandemic. In the prepandemic steady state, all individuals are susceptible, financial constraints are non-binding, and the only government policy is the existing UI program. Table 1 summarizes the calibrated parameters.

Externally calibrated parameters. The model period is one week. The utility function is given by $u(c)=\bar{u}+\frac{c^{1-\sigma}}{1-\sigma}$ as in Hall and Jones (2007), so that agents value life. We set $\sigma=2$ and discuss the calibration strategy for $\bar{u}$ below.

We assume a CES matching function, implying that the job finding rate is $f(\theta)=\theta\left(1+\theta^{\eta}\right)^{-1 / \eta}$. We set the matching function elasticity $\eta$ to 0.4 (Hagedorn and Manovskii, 2008). We follow Gascon (2020), who measures the employment share of essential occupations and those that can be done remotely, and assign the essential sector an employment share of 54 percent. Furthermore, we assume that 80 percent of the firms in the nonessential sector become financially constrained at the onset of the epidemic ( $\omega=0.8)$. Fujita and Moscarini (2017) show that the probability of exiting from unemployment through a recall approaches zero after six months of unemployment. This requires setting the stochastic expiration rate of the recall option $\chi_{r}$ to $1 / 26$. We set the worker's share of the output to $\phi=2 / 3$. Finally, we target a pre-COVID monthly separation rate of 1.65 percent computed using the Current Population Survey (CPS), and set $\delta$ to 0.0042 .

To discipline the model's SIR component, we follow Eichenbaum, Rebelo, and Trabandt (2020). Assuming a mortality rate of 0.5 percent and that infected individuals either recover or die from infection within 18 days, on average $\left(\pi^{D}+\pi^{R}=7 / 18\right)$, we obtain $\pi^{D}=0.005 \times 7 / 18$ and $\pi^{R}=$ $(1-0.005) \times 7 / 18$. Finally, we normalize the productivity of susceptible and recovered workers, $\alpha^{S}$ 


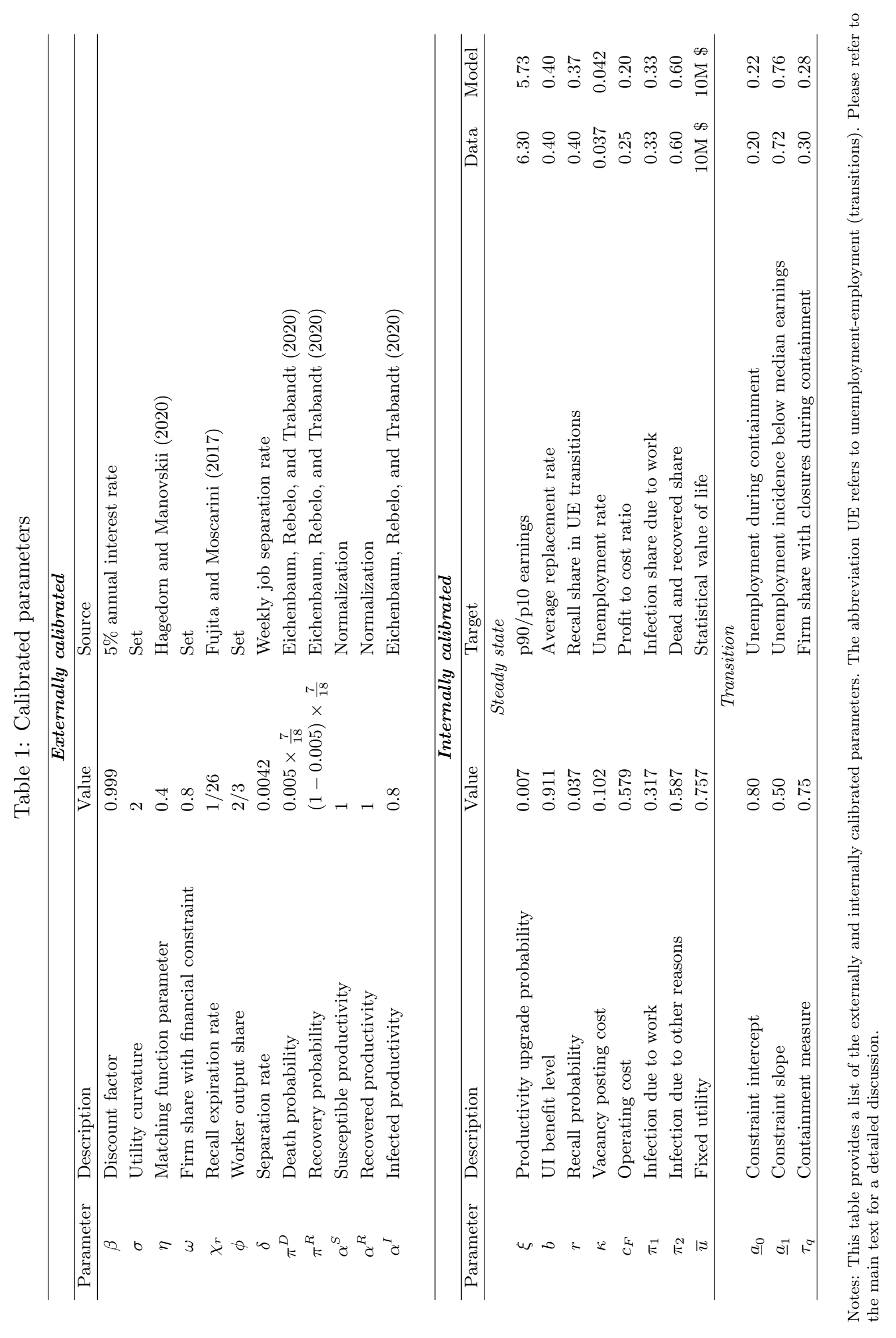


and $\alpha^{R}$, to one and assume a 20 percent loss in productivity when infected, i.e., $\alpha^{I}=0.8$.

Internally calibrated parameters. We calibrate eight of the remaining 11 parameters to match steady-state moments of the U.S. economy prior to the pandemic and the remaining three by simulating the COVID-19 pandemic and matching moments along the transition.

First, we discuss the steady-state moments. The probability $\xi$ of a productivity upgrade for actively producing a match has a pronounced effect on the earnings dispersion. Therefore, we target the 90th to the 10th percentile ratio of the labor earnings distribution among employed workers, which is 6.30 in the Survey of Program and Income Participation (SIPP).

Next, we target a replacement rate of 40 percent to discipline the UI payments $b$. The recall probability $r$ is chosen to match a 40 percent share of recalls in Unemployment-Employment (UE) flows (Fujita and Moscarini, 2017).

Firms face two costs. We choose the vacancy posting cost $\kappa$ to match an unemployment rate of 3.7 percent. Using aggregate income statements from the Internal Revenue Service (IRS), we find that, in 2017, the ratio of profits to business expenses is around 25 percent for sole proprietorships. We calibrate the fixed operating costs active firms incur $c_{F}$ to match this ratio.

We now describe the calibration of the parameters related to the epidemic. We choose $\pi_{1}$ such that the infections resulting from labor market activity account for one-third of all infections. To pin down $\pi_{2}$, we target a 60 percent combined share of recovered and dead individuals in a simple SIR model with no behavioral response from households. ${ }^{10}$ Finally, because $\bar{u}$ governs how much individuals value life over death, we choose $\bar{u}$ to match a statistical value of life of $\$ 10$ million as in Glover et al. (2020). Appendix A.3 provides more details.

Finally, we calibrate the remaining three parameters by simulating the COVID-19 pandemic and matching moments along the transition. Specifically, we populate the economy with an initial mass of 0.001 infected individuals. ${ }^{11}$ We assume that financial constraints in the nonessential sector become operational and that the only government response is to implement a containment measure $\tau_{q}$ in the nonessential sector during the first quarter of the pandemic.

The financial constraint is important for our substantive results, so we discuss its calibration in more detail. The constraint depends linearly on productivity: $\underline{a}(z)=\underline{a}_{0}+\underline{a}_{1} z$. The constant $\underline{a}_{0}$ has a pronounced effect on the unemployment level during the epidemic. We choose this to match a maximum unemployment rate of 20 percent for the first quarter of the epidemic. ${ }^{12}$ The slope of the constraint, $\underline{a}_{1}$, determines which matches are predisposed to separation during the epidemic. If $\underline{a}_{1}=0$, then wage rigidity implies that high-wage matches get destroyed. In contrast, a positive

\footnotetext{
${ }^{10}$ To do so, we simulate the system of equations given in Equation (A1) in Appendix A.1 under $\pi_{1}=0$ and calculate the total number of recovered and dead individuals in the steady state as a share of the initial population.

${ }^{11}$ We apportion this total initial infected mass to different labor market states, based on the population shares of the workers in the steady state.

${ }^{12}$ During the early stages of the shutdown in the U.S., there were many estimates of the peak unemployment rate in the absence of a policy response. Şahin, Tasci, and Yan (2020) estimated 16 percent; Treasury Secretary Steven Mnuchin noted a peak of 25 percent; and Faria-e Castro (2020a) estimated 32.1 percent. In our baseline calibration, we take 20 percent as our target. Later, in Table 2, we also show the results when unemployment peaks at 35 percent under stricter containment measures.
} 
$\underline{a}_{1}$ makes low-wage matches more likely to dissolve. Since $\underline{a}_{1}$ determines the wage composition of job losses, we choose it to match the incidence of the rise in unemployment across the earnings distribution. Using the CPS, we divide occupations into employment-weighted earnings quantiles. For each quantile, we calculate the change in temporary unemployment from January 2020 to April 2020. We find that occupations below the median of the earnings distribution account for 72 percent of the total increase in temporary unemployment. ${ }^{13}$ We target this moment to discipline $\underline{a}_{1}$.

Finally, we choose the strictness of the containment policy $\tau_{q}$ to match the fraction of businesses with temporary closings during the pandemic. According to the Small Business Pulse Survey of the U.S. Census Bureau, the fraction of businesses that temporarily closed for at least one day during any week of May 2020 was around 30 percent. We map temporary closings to firms pausing production in the model and calculate the fraction of idle matches in the nonessential sector.

\section{Results}

We now analyze the effects of an epidemic under various labor market policies. We start with a baseline containment of $\tau_{q}=0.75$ and no accompanying fiscal support, which we compare to two extreme cost-equivalent options: channel all additional transfers either through UI or through payroll subsidies. We then solve for the optimal mix of these policies and consider how this mix changes with the strictness of the containment. In all our experiments, we assume that policies are introduced coincident with the epidemic's onset and that they last for one quarter (13 weeks). ${ }^{14}$

No fiscal response. Figure 1 shows the results. Within a year, around 80 percent of the population is infected and eventually recovers, resulting in the deaths of 0.43 percent of the initial population. ${ }^{15}$ The unemployment rate in the nonessential sector rises to around 40 percent, resulting in a peak aggregate unemployment rate of 22 percent. In the data, around three-fourths of the total increase in unemployment is attributable to occupations below the median of the earnings distribution (Section 3). Since our model is calibrated to match this feature, layoffs in the nonessential sector are concentrated among these lower-quality matches, which face stricter financial constraints and smaller surpluses. This leads to a short-lived rise in average labor productivity during the containment. Permanently dissolved matches result in the loss of match capital built over time. As new but lowest-productivity $\left(z_{0}\right)$ matches are formed post-containment, nonessential ALP falls to nine percent below the steady state and remains persistently low. In the essential sector, which is not subject to containment, a limited drop in the ALP is driven mostly by infections reducing worker productivity. As such, this provides a benchmark on the effects of infection-related produc-

\footnotetext{
${ }^{13}$ Amburgey and Birinci (2020) find job losses to be more prevalent for low-income workers within the sample of temporary layoffs and that of all unemployed workers.

${ }^{14}$ We also consider longer containment measures. A containment policy that lasts two quarters has a larger impact on match surplus, thereby making higher-productivity matches more likely to terminate relative to a shorter containment. This raises the value of granting payroll subsidies that can save these jobs.

${ }^{15}$ Our model predicts a high infection rate relative to the data because our exercise only limits contagion through reduced economic activity but it does not account for other behavioral responses such as social distancing, increased hygiene, and the use of protective equipment that may reduce infections, which could be captured by a lower $\pi_{2}$. Furthermore, the reported data on infections are beset by undercounting due to hidden cases, testing constraints, and asymptomatic individuals.
} 
Figure 1: No Fiscal Response to Containment Measures in an Epidemic
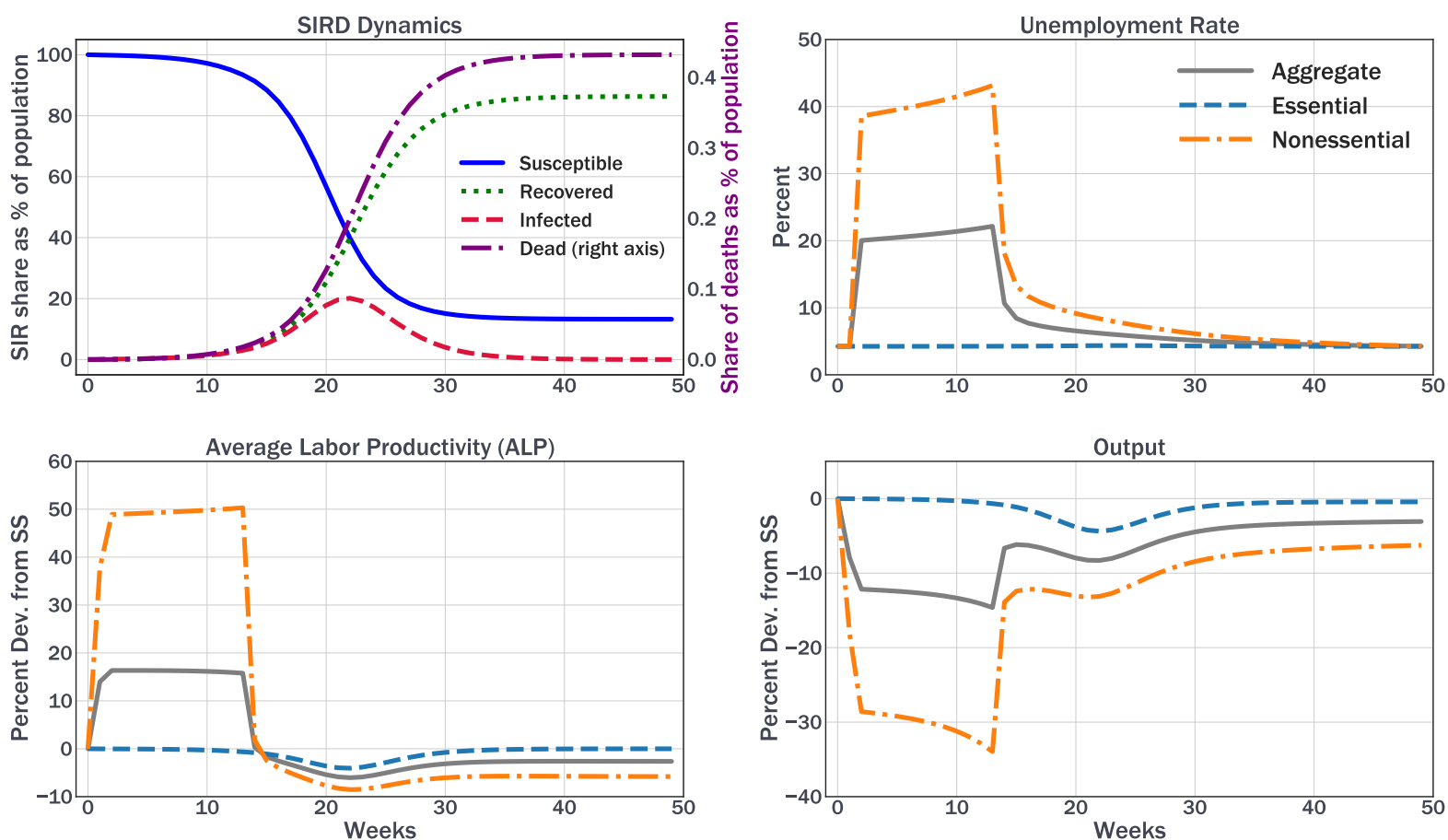

Notes: This figure plots the effects of the epidemic on Susceptible-Recovered-Infected-Dead (SIRD) and labor market dynamics when a containment is implemented for one quarter without any accompanying fiscal response. SS refers to steady state. Percent Dev. means the percent deviation from the steady state.

tivity losses. Meanwhile, aggregate output declines by 14 percent during containment. Despite the full employment recovery within one year, aggregate output remains three percent lower than its pre-crisis level due to the loss of match capital built over long-term employment relationships.

UI vs. payroll subsidies. We now study the expansion of the UI program and payroll subsidies one at a time. The UI benefit expansion is motivated by the CARES Act, which provides an additional $\$ 600$ per person in weekly unemployment benefits on top of regular payments that average $\$ 400$. To make cost-equivalent comparisons, we consider an alternative where the cost incurred by this UI expansion is instead diverted toward payroll subsidies, implying $\tau_{p}=0.47 .{ }^{16}$ Figure 2 plots the infection dynamics and labor market outcomes under these two cases. Relative to the no-fiscal-response scenario, the UI expansion results in a larger increase in unemployment driven by additional permanent dissolutions since a high value of unemployment yields a negative surplus for low-value matches. In contrast, payroll subsidies dampen the rise in unemployment by preventing the temporary layoffs that would otherwise be undertaken by financially constrained firms. The larger reduction in economic activity under the UI expansion leads to a slower rise

\footnotetext{
${ }^{16}$ In the baseline calibration, $b=0.911$ corresponds to an average weekly benefit amount of $\$ 400$ and a 40 percent replacement rate. Under the CARES Act, the total weekly benefit amount in the model then becomes $2.5 \times b$. The present discounted value of providing the additional benefit amount of $1.5 \times b$ over a quarter is cost-equivalent to the 47 percent payroll subsidy provided to firms in the nonessential sector over one quarter.
} 
Figure 2: UI Expansion vs. Payroll Subsidies
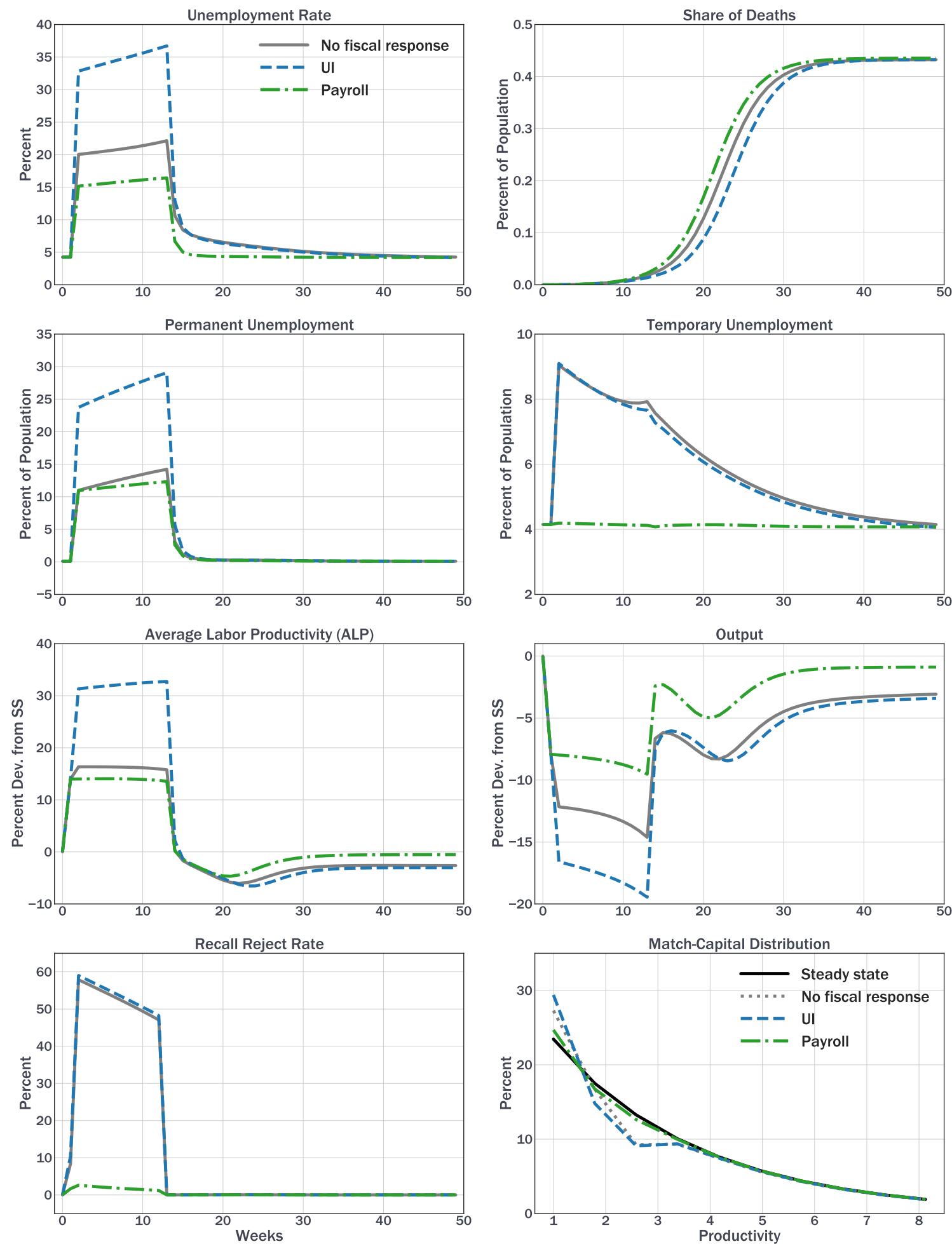

Notes: This figure plots the effects of the epidemic on health and labor market dynamics when the government implements a containment i) without any accompanying fiscal response, ii) with only an expansion in the UI policy for one quarter, or iii) with only an introduction of payroll subsidies for one quarter. The present discounted value of government spending under only a UI expansion and only a payroll subsidy are equal. In all figures except the last one, the horizontal axes denote weeks. 
Figure 3: Optimal Policy Mix
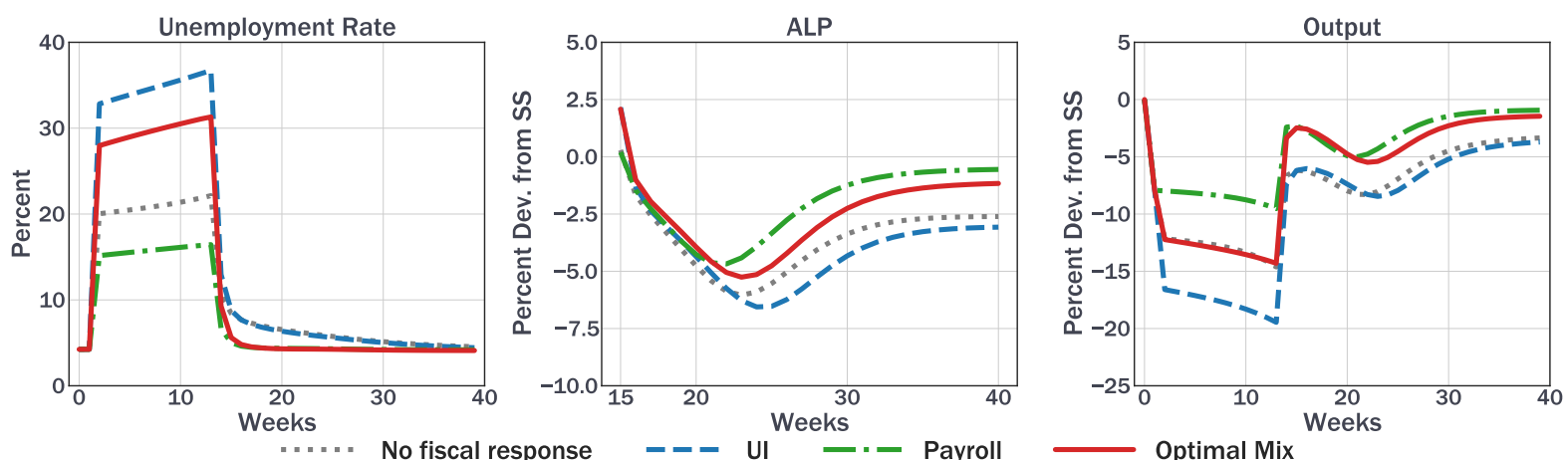

Notes: This figure plots the effects of the epidemic on labor market dynamics when the government implements a containment i) without any accompanying fiscal response, ii) with only an expansion of the UI policy for one quarter, iii) with only an introduction of payroll subsidies for one quarter, and iv) with the optimal policy mix for one quarter. The present discounted value of government spending under only a UI expansion, only a payroll subsidy, or the optimal policy mix are equal. In the middle panel, we plot the average labor productivity (ALP) after the containment period ends.

in infections and, thus, to both a delay and a decline in the number of deaths. ${ }^{17}$ Under the UI expansion, ALP rises temporarily due to the destruction of low-productivity matches but it also experiences a more-severe and persistent fall to seven percent below pre-crisis levels. The ALP dynamics post-containment mirror a similarly persistent drop in output. In contrast, payroll subsidies allow firms to retain their matches without resorting to temporary layoffs that may eventually dissolve if recalls do not materialize. Conditional on being temporarily laid off, payroll subsidies also increase the incidence of recalls, given that firms engaged in rehiring are less likely to face financial constraints that may cause recall rejections. These result in a less-severe drop and faster recovery of both ALP and output. In order to understand ALP and output dynamics, the final panel of Figure 2 compares the match-capital distribution pre- (steady state) and post-containment under different policy responses. Under the no-fiscal-response scenario (gray line), relative to the steady state, the post-containment distribution shifts toward low-match capital jobs as accumulated capital is destroyed. This effect is exacerbated by the UI expansion (blue line), but payroll subsidies (green line) preserve match capital so much so that the post-containment employment distribution remains close to the pre-crisis steady state. The distributions demonstrate that the UI expansion and payroll subsidies have differential effects on the productivity ladder - the former causes workers to fall off the ladder but provides insurance to job losers, while the latter preserves workers' positions along the ladder but is a less-potent direct insurance mechanism for job losers. In terms of welfare, relative to the no-fiscal-response scenario, the UI expansion results in a welfare gain equivalent to 0.18 percent of additional lifetime consumption, while payroll subsidies result in a welfare gain of 0.76 percent. ${ }^{18}$ This implies that when considered in isolation, a payroll subsidy

\footnotetext{
${ }^{17}$ The payroll subsidy program results in roughly 15,000 more deaths after one year. Since we do not model how delaying infections under the UI expansion may result in the improved preparedness of the health system, we view this difference in the death toll as a lower bound. However, in the absence of an option to pause production, the death gap between the UI and the payroll options would be higher, given that, in the current model, some firms that receive payroll subsidies choose to pause production.

${ }^{18}$ See Appendix A.4 for details of the welfare calculation.
} 
Figure 4: Match-Capital Distribution
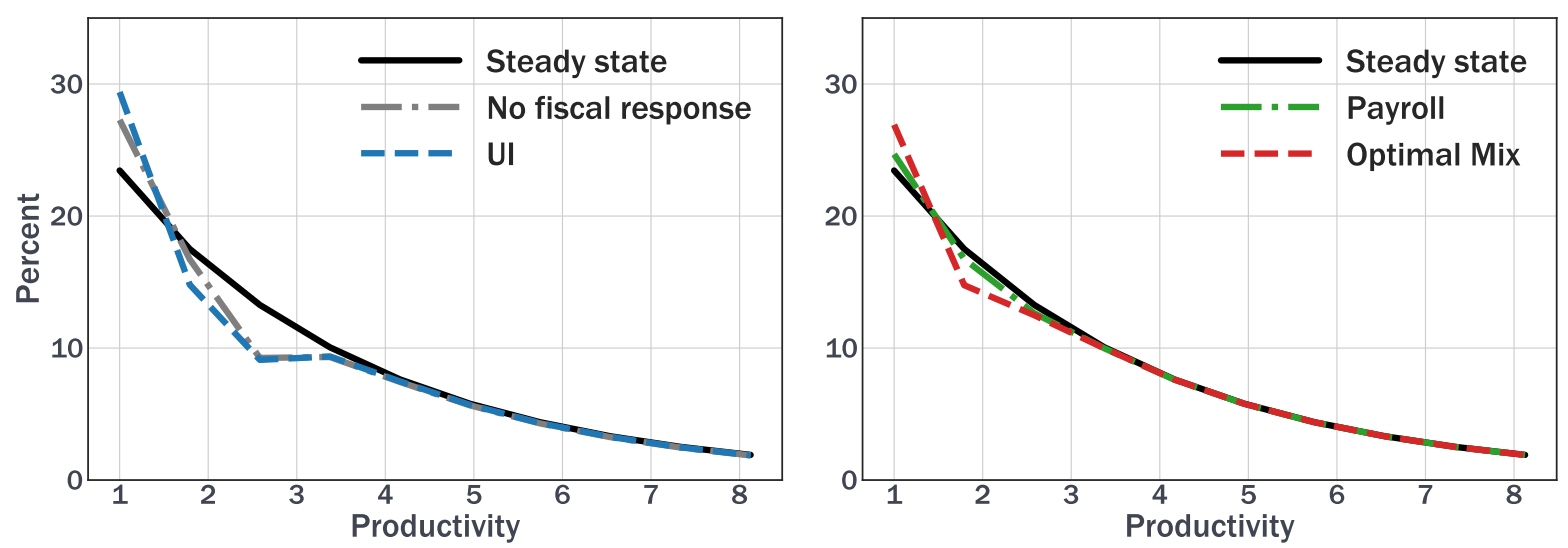

Notes: This figure plots the pre-containment (steady state) and post-containment (seven weeks after the containment) matchcapital distribution. The post-containment distributions are shown separately for the following scenarios: i) having no fiscal response, ii) only expanding UI benefits, iii) only introducing payroll subsidies, and iv) implementing the optimal policy mix.

is preferred over a cost-equivalent UI expansion.

Optimal mix of policies. What is the optimal policy mix? Given a baseline containment rate of $\tau_{q}=0.75$, we solve for $b$ and $\tau_{p}$ to maximize welfare subject to preserving the cost equivalence with the preceding exercise. The optimal policy prescribes an 80 percent budget allocation toward UI while the remaining 20 percent is spent on payroll subsidies, yielding a welfare gain of 0.85 percent in additional lifetime consumption relative to a no-fiscal-response alternative. This implies $b^{*}=2.20$ and $\tau_{p}^{*}=0.10$. The left-hand column of Figure 3 shows that under the optimal policy, the relatively generous UI payments induce a large increase in unemployment, more than halfway between the no-fiscal-response and the full-UI scenarios. However, the 10 percent payroll subsidy goes a long way toward preserving match capital, as evidenced by the less-severe drop in ALP. An important implication is that even if the unemployment rate is drastically higher under the optimal policy (red) relative to having no fiscal response (gray), the output during containment is the same and recovers much faster under the optimal policy. The faster recovery occurs because firm-worker pairs with high match capital resume production once the containment period ends. This is supported by the left-hand column of Figure 4, where the match-capital distribution significantly worsens under both no fiscal response (gray) and full UI (blue), but the optimal policy with only $\tau_{p}^{*}=0.1$ (red) is capable of preserving match capital close to steady-state levels and, importantly, accomplishes what a large payroll subsidy of $\tau_{p}=0.47$ (green) would have achieved. This brings us to two important conclusions. First, a payroll subsidy that is just enough to prevent high-productivity matches from dissolving eliminates the need for generous subsidies in excess of what firms need to weather the containment period. Second, UI and payroll subsidies target workers on different rungs of the productivity ladder. On the one hand, payroll subsidies seek to preserve matches for highly productive workers and prevent their flow into unemployment. On the other hand, for less-productive matches predisposed to dissolution even with payroll subsidies, UI serves as an 
Table 2: Robustness and comparative statics

\begin{tabular}{lcccccccc}
\hline & Baseline & $1.2 \tau_{q}$ & $1.25 r$ & $1.5 r$ & $0.5 \xi$ & $2 \xi$ & $0.75 \underline{a}_{1}$ & $0.25 \underline{a}_{1}$ \\
\hline UI in isolation & 0.18 & 0.24 & 0.18 & 0.17 & 0.17 & 0.13 & 0.17 & 0.15 \\
Payroll subsidy in isolation & 0.76 & 3.34 & 0.73 & 0.70 & 0.75 & 0.72 & 1.14 & 1.08 \\
Optimal mix & 0.85 & 3.42 & 0.81 & 0.79 & 0.84 & 0.80 & 1.23 & 1.12 \\
$\quad$ Budget share of UI, \% & 80.2 & 57.9 & 83.1 & 83.0 & 83.2 & 47.1 & 74.7 & 34.4 \\
\hline
\end{tabular}

Notes: This table summarizes welfare outcomes under different parametrizations of the model. "Baseline" refers to the calibration in Table 1. The other columns refer to parameterizations where the strictness of lockdown $\tau_{q}$, recall probability $r$, productivity upgrade probability $\xi$, or the slope of the financial constraint $\underline{a}_{1}$ are varied. Welfare gains are reported in percent consumption equivalent units. The last row reports the share of total spending on UI in the optimal policy mix.

insurance mechanism to smooth consumption. Thus, when considered in isolation, payroll subsidies prevail over UI expansions, but under an optimal policy mix, these two policies are complementary. A partial allocation of resources for payroll subsidies preserves match capital and also leaves a substantial budgetary space for additional UI payments for the inevitable increase in job losses.

Why does the optimal mix allocate a smaller share of funds to payroll subsidies when they achieve a larger welfare gain relative to UI in isolation? The key to this result is the observation that the welfare gain from each dollar spent on payroll subsidies exhibits diminishing returns for two reasons. First, as more funds are allocated to subsidies (a higher $\tau_{p}$ ), the marginal job preserved declines in productivity and this additional spending has a negligible effect on stimulating a faster recovery. Second, since all firms benefit from subsidies at the same rate, further increasing $\tau_{p}$ implies paying additional, unnecessary subsidies to high-productivity firms that do not face dissolution risk. To illustrate the diminishing returns quantitatively, we calculate the welfare gain of a policy where the government spends 20 percent of the budget on payroll subsidies and does not change the generosity of UI benefits. The welfare gain of such a policy is 0.75 percent, very close to the 0.76 percent welfare gain from spending the entire budget on payroll subsidies. Given these diminishing returns, the optimal policy prefers the permanent dissolution of low-productivity matches and uses the remaining funds to insure workers in those matches through UI. ${ }^{19}$

Robustness and comparative statics. Do payroll subsidies always dominate UI expansion in isolation? Does the optimal mix always allocate more funds to UI expansion? We investigate how our results depend on several parameters with two goals. First, this allows us to better understand and illustrate the economic forces behind the main results. Second, while our analysis is primarily calibrated to the U.S. economy, similar trade-offs should be present in other countries as well. During the pandemic, other countries could have differed in the strength of their containment measures, the importance of their match capital, the extent of their financial frictions, or how pervasive their recalls are. Our analysis can therefore speak to why different countries may find it optimal to implement different policy mixes.

We consider differences in the stringency of containment $\left(\tau_{q}\right)$, recall probabilities $(r)$, the speed

\footnotetext{
${ }^{19}$ Recall that the welfare gain from implementing the optimal mix is 0.85 percent, implying that 80 percent of the budget spent on UI expansion provides an additional 0.10 percentage point welfare gain.
} 
of learning on the job $(\xi)$, and how financial frictions vary across firms with different productivities $\left(\underline{a}_{1}\right)$. For each exercise, we compute the welfare gain of introducing either a UI expansion or a payroll subsidy in isolation as well as the new optimal policy mix and its associated welfare gain. To ensure comparability, we choose the policy parameters $\tau_{p}$ and $b$ such that the policies are costequivalent with the baseline. In the case of financial frictions, we also recalibrate $\underline{a}_{0}$ to obtain the same peak unemployment as in our baseline. Our results are summarized in Table 2.

Under a stricter lockdown $\left(1.2 \tau_{q}\right)$, the no-fiscal-response scenario induces a higher peak unemployment rate (35 percent) and causes the dissolution of an even wider range of highly productive matches, thereby generating a larger decline in ALP and output (Figure A1 in Appendix A.5). Similar to the main exercise, allocating the entire budget to UI expansion exacerbates these effects because strict containment greatly depresses the surplus from high-productivity matches. Therefore, the optimal policy now prescribes less-generous UI benefits. Specifically, the optimal mix now allocates a lower fraction, 58 percent, of the budget on UI. The optimal policy significantly alleviates the drop in productivity and output, even during containment (Figure A1), and preserves the high-productivity matches that would otherwise have dissolved (Figure A2). As a result, the welfare gain from the optimal mix becomes much larger under strict containment. Once again, we note that the 42 percent budget allocation on payroll subsidies captures most of the gains that allocating the entire budget to payroll would have achieved (Figure A2).

A higher recall probability ensures that a lower share of temporary layoffs results in permanent match destruction and reduces the potential benefit of payroll subsidies. This effect is quantitatively small: A 25 or even 50 percent higher $r$ reduces the budget share allocated to payroll subsidies in the optimal mix from 20 percent to 17 percent. There are three reasons for why a higher recall probability results in only a modest decline in the share of spending on payroll subsidies: i) containment measures induce negative surpluses for some matches, leading to permanent separations that recalls cannot remedy, ii) productivity stagnates during temporary separations prior to recalls, and iii) a higher recall probability reduces but does not completely eliminate the permanent expiration of the recall option and the severance of ties between workers and firms.

The rate at which productivity grows on the job $(\xi)$ is an important determinant of the optimal policy. We discipline this parameter by targeting the wage dispersion in the data. An alternative approach is to target the earnings losses upon job loss because $\xi$ controls how much wages grow among job stayers relative to job losers. Reassuringly, our model does a good job in matching the initial earnings loss while understating losses in the longer term by about 5 percentage points (see Appendix A.6). Regardless of the fit, our estimate for $\xi$ may be biased upward. This is because the inequality and the consequences of job loss in the data are shaped by a host of factors apart from differences in the match productivity alone. To gauge the robustness of our conclusions, we solve for the optimal policy by setting $\xi$ to double that of the baseline value and then to half the baseline value. Raising $\xi$ by a factor of two makes long-tenure matches much more productive, thereby increasing the benefit of payroll subsidies. Consequently, the optimal policy allocates 53 percent of the budget to this component. Conversely, lowering $\xi$ dictates a lower share to be allocated 
to payroll subsidies, given the reduced importance of match-specific capital. In isolation, payroll subsidies still provide a much larger welfare gain relative to a cost-equivalent UI expansion.

Another important aspect is the relationship between financial frictions and match productivity governed by $\underline{a}_{1}$. Whether constraints bind more for high- or low-productivity firms is important for the policy tradeoff. A lower $\underline{a}_{1}$ implies a tighter constraint for high-productivity matches. When these output-critical jobs are more predisposed to permanent dissolution, match preservation through payroll subsidies becomes more important. We find that reducing $\underline{a}_{1}$ down to a quarter of its baseline value increases the optimal spending on payroll subsidies to a level that is twice the proportion spent on UI. However, such a low value for $\underline{a}_{1}$ implies that separations from low-paying jobs (below the median wage) account for only 11 percent of the total increase in unemployment. This number is clearly at odds with the 72 percent share observed in the data, which is an integral part of how we discipline the distribution of job losses in our model.

\section{Conclusion}

The COVID-19 pandemic and the ensuing policy interventions to contain it have had unprecedented negative effects on the U.S. labor market. In response, the U.S. government implemented two types of labor market policies: expanding UI payments and granting payroll subsidies to vulnerable firms. In this paper, we study the usefulness of these policies, both in isolation and in conjunction. The introduction of payroll subsidies alone is preferred over a cost-equivalent UI expansion as it preserves highly productive matches during containment, thus enabling a faster recovery of productivity and output following the lifting of containment measures. When considered jointly, however, a costequivalent optimal mix allocates 20 percent of the budget to payroll subsidies and 80 percent to UI expansion. This allocation is sufficient to save high-productivity jobs from dissolution, while the remaining funds are used to provide income to less-productive workers who face inevitable job loss.

We abstract away from two potentially important margins. First, we assume away labor mobility across sectors. If the pandemic has a disproportionately persistent effect on labor demand in one of the sectors, then policies that tie workers to jobs, such as payroll subsidies, would become less desirable. Second, we abstract away from welfare gains due to demand stabilization. Because payroll subsidies and UI policies benefit different groups of people with potentially different marginal

propensities to consume, their effects on aggregate demand may be different. We leave these important considerations for future research.

\section{References}

Alon, T., M. Doepke, J. Olmstead-Rumsey, and M. Tertilt (2020): "This time it's different: The role of women's employment in a pandemic recession," Tech. rep., National Bureau of Economic Research. Alvarez, F. E., D. Argente, And F. Lippi (2020): "A simple planning problem for covid-19 lockdown," Tech. rep., National Bureau of Economic Research.

Amburgey, A. AND S. BiRINCI (2020): "Which earnings groups have been most affected by the COVID-19 crisis?" Economic Synopses. 
Atkeson, A. (2020): "What will be the economic impact of Covid-19 in the US? Rough estimates of disease scenarios," Tech. rep., National Bureau of Economic Research.

Berger, D. W., K. F. Herkenhoff, and S. Mongey (2020): "An seir infectious disease model with testing and conditional quarantine," Tech. rep., National Bureau of Economic Research.

Bick, A. ANd A. Blandin (2020): "Real time labor market estimates during the 2020 coronavirus outbreak," Unpublished Manuscript, Arizona State University.

Birinci, S. (2020): "Spousal labor supply response to job displacement and implications for optimal transfers," Tech. rep., Federal Reserve Bank of Saint Louis.

Birinci, S. AND K. SeE (2020): "How should unemployment insurance vary over the business cycle?" Tech. rep., Federal Reserve Bank of St. Louis.

Boar, C. And S. Mongey (2020): "Dynamic trade-offs and labor supply under the CARES Act," Tech. rep., National Bureau of Economic Research.

Brotherhood, L., P. Kircher, C. Santos, and M. Tertilt (2020): "An economic model of the Covid19 pandemic with young and old agents: Behavior, testing and policies," Tech. rep., University of Bonn and University of Mannheim, Germany.

Burdett, K. And R. Wright (1989): "Unemployment insurance and short-time compensation: The effects on layoffs, hours per worker, and wages," Journal of Political Economy, 97, 1479-1496.

Cahuc, P., F. Kramarz, S. Nevoux, et Al. (2018): "When short-time work works," Tech. rep., Sciences Po Departement of Economics.

Chodorow-Reich, G., J. Coglianese, and L. Karabarbounis (2019): "The macro effects of unemployment benefit extensions: a measurement error approach," The Quarterly Journal of Economics, 134, $227-279$.

Cooper, R., M. Meyer, And I. Schott (2017): "The employment and output effects of short-time work in Germany," Tech. rep., National Bureau of Economic Research.

Davis, S. J. And T. von Wachter (2011): "Recessions and the Costs of Job Loss," Brookings Papers on Economic Activity, 1.

Eichenbaum, M. S., S. Rebelo, and M. Trabandt (2020): "The macroeconomics of epidemics," Tech. rep., National Bureau of Economic Research.

FAnG, L., J. Nie, And Z. XIE (2020): "Unemployment insurance during a pandemic," Tech. rep., Federal Reserve Bank of Atlanta.

FAria-e Castro, M. (2020a): "Back-of-the-envelope estimates of next quarter's unemployment rate," Saint Louis Fed Blogs.

— (2020b): "Fiscal policy during a pandemic," FRB St. Louis Working Paper.

Fujita, S. And G. Moscarini (2017): "Recall and unemployment," American Economic Review, 107, 3875-3916.

Ganong, P., P. J. Noel, And J. S. Vavra (2020): "US unemployment insurance replacement rates during the pandemic," Tech. rep., National Bureau of Economic Research.

Garriga, C., R. Manuelli, and S. Sanghi (2020): "Optimal management of an epidemic: Lockdown, vaccine and value of life," Tech. rep., Federal Reserve Bank of St. Louis.

GASCON, C. (2020): "COVID-19: Which workers face the highest unemployment risk?" St. Louis Fed On the Economy, https://www. stlouisfed. org/on-the-economy/2020/march/covid-19-workers-highestunemployment-risk.

Giupponi, G. And C. Landais (2020): "Subsidizing labor hoarding in recessions: The employment \& welfare effects of short time work," Working paper. 
Glover, A., J. Heathcote, D. Krueger, and J.-V. Ríos-Rull (2020): "Health versus wealth: On the distributional effects of controlling a pandemic," Tech. rep., National Bureau of Economic Research.

Gregory, V., G. Menzio, And D. G. Wiczer (2020): "Pandemic recession: L or V-shaped?" Tech. rep., National Bureau of Economic Research.

Hagedorn, M., F. Karahan, I. Manovskit, and K. Mitman (2019): "Unemployment benefits and unemployment in the great recession: the role of macro effects," Tech. rep., National Bureau of Economic Research.

Hagedorn, M. and I. Manovski (2008): "The cyclical behavior of equilibrium unemployment and vacancies revisited," American Economic Review, 98, 1692-1706.

Hall, R. E. And C. I. Jones (2007): "The value of life and the rise in health spending," The Quarterly Journal of Economics, 122, 39-72.

Jacobson, L. S., R. J. LaLonde, And D. G. Sullivan (1993): "Earnings losses of displaced workers," American economic review, 685-709.

Jarosch, G. (2015): "Searching for job security and the consequences of job loss," Tech. rep., Princeton University.

Jung, P. And K. Kuester (2015): "Optimal labor-market policy in recessions," American Economic Journal: Macroeconomics, 7, 124-56.

KAPICKA, M. AND P. Rupert (2020): "Labor markets during pandemics," Manuscript, UC Santa Barbara.

Kermack, W. O. ANd A. G. McKendrick (1927): "A contribution to the mathematical theory of epidemics," Proceedings of the royal society of london. Series A, Containing papers of a mathematical and physical character, 115, 700-721.

Kolsrud, J., C. Landais, P. Nilsson, And J. SpinnewiJn (2018): "The optimal timing of unemployment benefits: Theory and evidence from Sweden," American Economic Review, 108, 985-1033.

Krusell, P., T. Mukoyama, And A. Şahin (2010): "Labour-market matching with precautionary savings and aggregate fluctuations," The Review of Economic Studies, 77, 1477-1507.

Kurmann, A., E. Lale, And L. Ta (2020): "The impact of COVID-19 on U.S. employment and hours: Real-time estimates with homebase data," Tech. rep., Drexel University.

Landais, C., P. Michaillat, and E. Saez (2018): "A macroeconomic approach to optimal unemployment insurance: Applications," American Economic Journal: Economic Policy, 10, 182-216.

Mitman, K. AND S. Rabinovich (2015): "Optimal unemployment insurance in an equilibrium businesscycle model," Journal of Monetary Economics, 71, 99-118.

- (2020): "Optimal unemployment benefits in the pandemic," Tech. rep., IZA Discussion Papers.

NAKAJima, M. (2012): "A quantitative analysis of unemployment benefit extensions," Journal of Monetary Economics, 59, 686-702.

ŞAHIN, A., M. TASCI, AND J. YAN (2020): "The unemployment cost of COVID-19: How high and how long?" Economic Commentary.

Stevens, A. H. (1997): "Persistent effects of job displacement: The importance of multiple job losses," Journal of Labor Economics, 15, 165-188.

Tilly, J. And K. Niedermayer (2016): "Employment and welfare effects of short-time work," Tech. rep., Working paper. 


\section{A Appendix}

\section{A.1 Stationary Equilibrium}

Let $s \in\{E, N\}$ denote the essential $E$ and nonessential $N$ sectors. A recursive equilibrium for this economy is a list of household and firm policy functions for whether to keep an existing match $d_{W, k, s}^{h}, d_{U_{T}, k, k^{\prime}, s}^{h}$, and $d_{J, k, s}^{h}$; whether to produce or pause $l_{s}^{h}, \forall h \in\{S, I, R\}, \forall s \in\{E, N\}$, and $\forall k \in\{C, U\}$; labor market tightness $\theta_{s} \forall s \in\{E, N\}$; an aggregate law of motion for the mass of susceptible $S$, infected $I$, recovered $R$, and dead $D$ agents; and the distribution of households across states $\mu$ such that,

1. given government policies, household and firm policy functions solve their problems;

2. labor market tightness in sector $s$ satisfies the free-entry condition $V=0$;

3. the aggregate laws of motion for health status are given by

$$
\begin{aligned}
S_{t+1} & =S_{t}-T_{t} \\
I_{t+1} & =I_{t}+T_{t}-\left(\pi^{R}+\pi^{D}\right) I_{t} \\
R_{t+1} & =R_{t}+\pi^{R} I_{t} \\
D_{t+1} & =D_{t}+\pi^{D} I_{t},
\end{aligned}
$$

where the total number of new infections in period $t$ is $T_{t}=\pi_{1} N_{t}^{S} N_{t}^{I}+\pi_{2} S_{t} I_{t}$ and $N^{h}$ is the total number of actively employed households with health status $h$; and

4. $\mu$ is the invariant distribution implied by contact rates in the labor market, transition matrices of health status $\Pi_{n}$ and of match-specific productivity $P$, and household and firm decision rules.

\section{A.2 Computational Details}

In this section, we describe how we solve and simulate our model.

\section{A.2.1 Steady State}

We use value function iteration to solve for worker and firm optimization problems. The algorithm we use to obtain the stationary equilibrium of the model is outlined below.

For a given parameterization of the model and for each sector $s \in\{E, N\}$, perform the following:

1. Start with an initial guess for the value of market tightness $\theta_{0}^{s}$.

2. For each guess of $\theta_{n}^{s}$ in iteration $n$ :

(a) Iterate over the worker and firm value functions in Equations (2), (3), (6), (7) and (8) until convergence.

(b) Iterate on the model-implied laws of motion in order to compute for the stationary worker distribution over employment states, health status and productivity. 
(c) Solve the market tightness level $\widetilde{\theta}_{n+1}^{s}$ that satisfies the free-entry condition $V=0$, where $V$ is given in Equation (9). We then calculate its absolute deviation from $\theta_{n}^{s}$.

(d) If the deviation is less than a tolerance level, then we stop. Otherwise we update the guess for market tightness to $\theta_{n+1}^{s}=\zeta \theta_{n}+(1-\zeta) \widetilde{\theta}_{n+1}^{s}$ with dampening parameter $\zeta<1$ and return to Step 2.

\section{A.2.2 Transition}

For each policy, in calculating the impulse responses, we focus on perfect foresight transition dynamics following one-time and unanticipated shocks out of the steady state, using a shooting algorithm as outlined below.

1. Fix the number of time periods it takes to reach the new steady state, $T$.

2. Compute the initial (no-infection) steady-state equilibrium for a given set of model parameters according to the algorithm in Section A.2.1. As the epidemic is transitory and there is no permanent productivity difference between susceptible and recovered workers, the worker and firm value functions in the terminal steady state are the same as in the initial steady state as is the labor market tightness for each sector.

3. Guess a sequence of infected workers' labor supply and the total number of infected in the economy as a whole, $\left\{N_{t}^{I, 0}, I_{t}^{0}\right\}_{t=1}^{T-1}$. For each sector $s \in\{E, N\}$ :

(a) Guess a sequence of labor market tightness $\left\{\theta_{t}^{s, 0}\right\}_{t=1}^{T-1}$.

(b) Solve for the path of worker and firm value functions for $t \in\{1, \ldots, T-1\}$ backwards, given the shocks, path of infection $\left\{N_{t}^{I, 0}, I_{t}^{0}\right\}_{t=1}^{T-1}$, market tightness $\left\{\theta_{t}^{s, 0}\right\}_{t=1}^{T-1}$, and terminal worker and firm values in period $T$.

(c) Compute the sequence of labor market tightness $\left\{\theta_{t}^{s, 1}\right\}_{t=1}^{T-1}$ that is consistent with the free-entry condition and the laws of motion for workers over the state space induced by the decisions implied by the path of value functions over $t \in\{1, \ldots, T-1\}$.

(d) Check whether $\max _{1 \leq t<T}\left|\theta_{t}^{s, 1}-\theta_{t}^{s, 0}\right|$ is less than some tolerance level. If yes, continue; if not, update $\left\{\theta_{t}^{s, 0}\right\}_{t=1}^{T-1}$ and go back to Step (b).

(e) Check whether $\left|\theta_{T}^{s, 1}-\theta_{T}^{s, 0}\right|$ is less than some tolerance level. If yes, then stop; if not, then increase $T$ and go back to Step 1.

4. Calculate the sequence of infected workers' labor supply and the total number of infected workers, $\left\{N_{t}^{I, 1}, I_{t}^{1}\right\}_{t=1}^{T-1}$, which is implied by the path of the worker distribution over the transition.

5. Check whether $\max _{1 \leq t<T}\left|N_{t}^{I, 1}-N_{t}^{I, 0}\right|$ and $\max _{1 \leq t<T}\left|I_{t}^{1}-I_{t}^{0}\right|$ are less than some tolerance level. If yes, then continue; if not, then update $\left\{N_{t}^{I, 0}\right\}_{t=1}^{T-1}$ and $\left\{I_{t}^{0}\right\}_{t=1}^{T-1}$ and return to Step 3.

6. Check whether $\left|N_{T}^{I, 1}-N_{T}^{I, 0}\right|$ and $\left|I_{T}^{1}-I_{T}^{0}\right|$ are less than some tolerance level. If yes, then stop; if not, then increase $T$ and go back to Step 1. 


\section{A.3 Computing the Statistical Value of Life}

To calculate the model-implied statistical value of life (SVL), we first compute the fraction of lifetime consumption $\pi$ all agents in the steady-state economy are willing to forgo in order to prevent a rise in the probability of death by $\psi=\frac{1}{10,000}$. We do this by resolving our no-infection model with a discount factor $\widetilde{\beta}=(1-\psi) \beta$ that is adjusted by this mortality rate and finding the $\pi$ that renders workers indifferent between these two economies behind the veil of ignorance.

Second, to convert the fraction $\pi$ to a dollar amount, we take the quarterly consumption amount from the National Income Accounts. U.S. consumption per capita in the fourth quarter of 2019 was $\$ 40,748$. We divide this number by 52.14 to arrive at a weekly consumption of $c_{w}^{N I P A}=\$ 781.5$. The model-implied weekly dollar amount that workers are willing to forgo is then given by $\pi \times c_{w}^{N I P A}$.

In the final step, we convert the weekly consumption that workers are willing to forgo into a present value term by taking its geometric sum; i.e. $\frac{\pi c_{w}^{N I P A}}{1-\beta}$. This implies that the total amount that workers are willing to pay to avoid one death is $\frac{1}{\psi} \frac{\pi c_{w}^{N I P A}}{1-\beta}$, which is the definition of SVL. We choose the constant $\bar{u}$ in the utility function such that $S V L=\$ 10 M$.

\section{A.4 Computing Welfare}

To compute a welfare metric, we solve for the percent change in lifetime consumption $\pi$ that renders a household behind the veil of ignorance indifferent between the baseline economy and the economy under a new labor market policy, accounting for all policy changes during the transition period. The expected value of a particular policy $p$ when that policy is implemented, is given by

$$
\mathbb{E} V(\pi, p) \equiv \sum_{t=1}^{T-1} \beta^{t-1}\left[\int u\left((1+\pi) c_{i t}(p)\right) d \Lambda_{i t}(p)\right]+\beta^{T-1} \int V_{i T}(\pi, p) d \Lambda_{i T}(p)
$$

where $c_{i t}(p)$ denotes the consumption of individual $i$ under policy $p$ in period $t, \Lambda_{i t}(p)$ is the cross-sectional cumulative density function of workers, and $V_{i T}(\pi, p)$ is the steady-state value of individual $i$, where they receive an additional $\pi$ percent of their consumption under that policy. The underlying assumption here is that the economy is close enough to its terminal steady state by the end of period $T$. In practice, we choose $T=500$ weeks in our computations, which we observe to be long enough for the economy to have converged to a stationary equilibrium.

Finally, to arrive at the welfare metric $\pi(p)$ under policy $p$, we solve the following condition:

$$
\mathbb{E} V(\pi, 0)=\mathbb{E} V(0, p),
$$

where we use the convention that $p=0$ denotes the baseline economy: i.e., there are no fiscal measures introduced. Otherwise, we consider $p \in\{\mathrm{UI}$, Payroll, Mix $\}$ for various policy scenarios.

\section{A.5 Additional Results on the Baseline vs the Stricter Containment Measures}

Below, we elaborate on the effects of stricter containment measures and how an optimal policy mix with more weight on payroll subsidies alleviates its economic burden.

As discussed in Section 4, increasing the strength of containment measures from $\tau_{q}=0.75$ by 
Figure A1: Optimal Policy Mix under the Baseline and Stricter Containment Measures
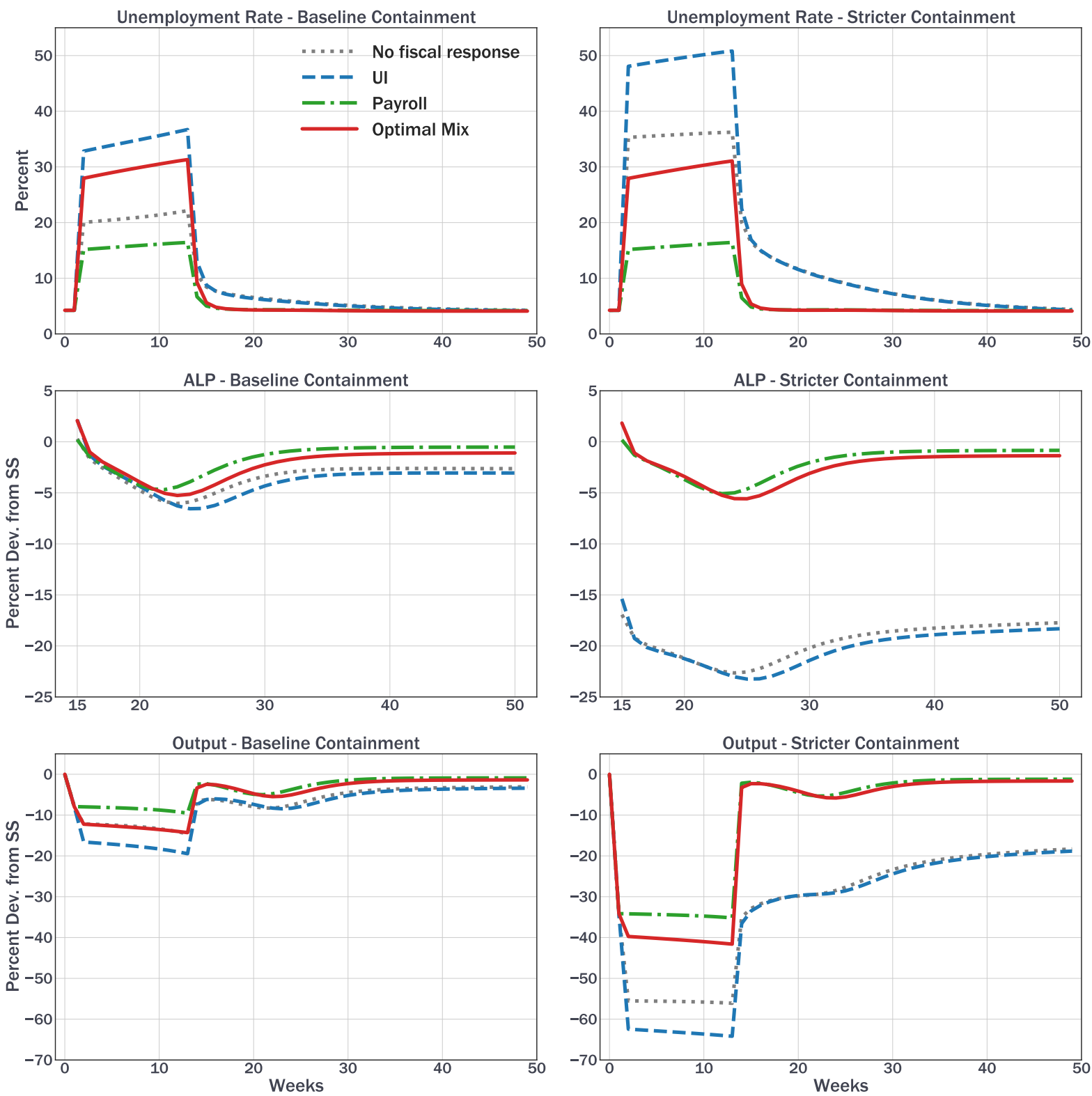

Notes: This figure compares the effects of the epidemic on the labor market dynamics in the baseline economy to an economy where the government implements stricter containment measures i) without any accompanying fiscal response, ii) with only an expansion of the UI policy for one quarter, iii) with only an introduction of payroll subsidies for one quarter, and iv) with the optimal policy mix for one quarter. The present discounted value of government spending under only a UI expansion, only a payroll subsidy, or the optimal policy mix are equal. In the second row of panels, we plot the average labor productivity (ALP) for the period after the containment ends. 
Figure A2: Match-Capital Distribution under both Baseline and Stricter Containment Measures
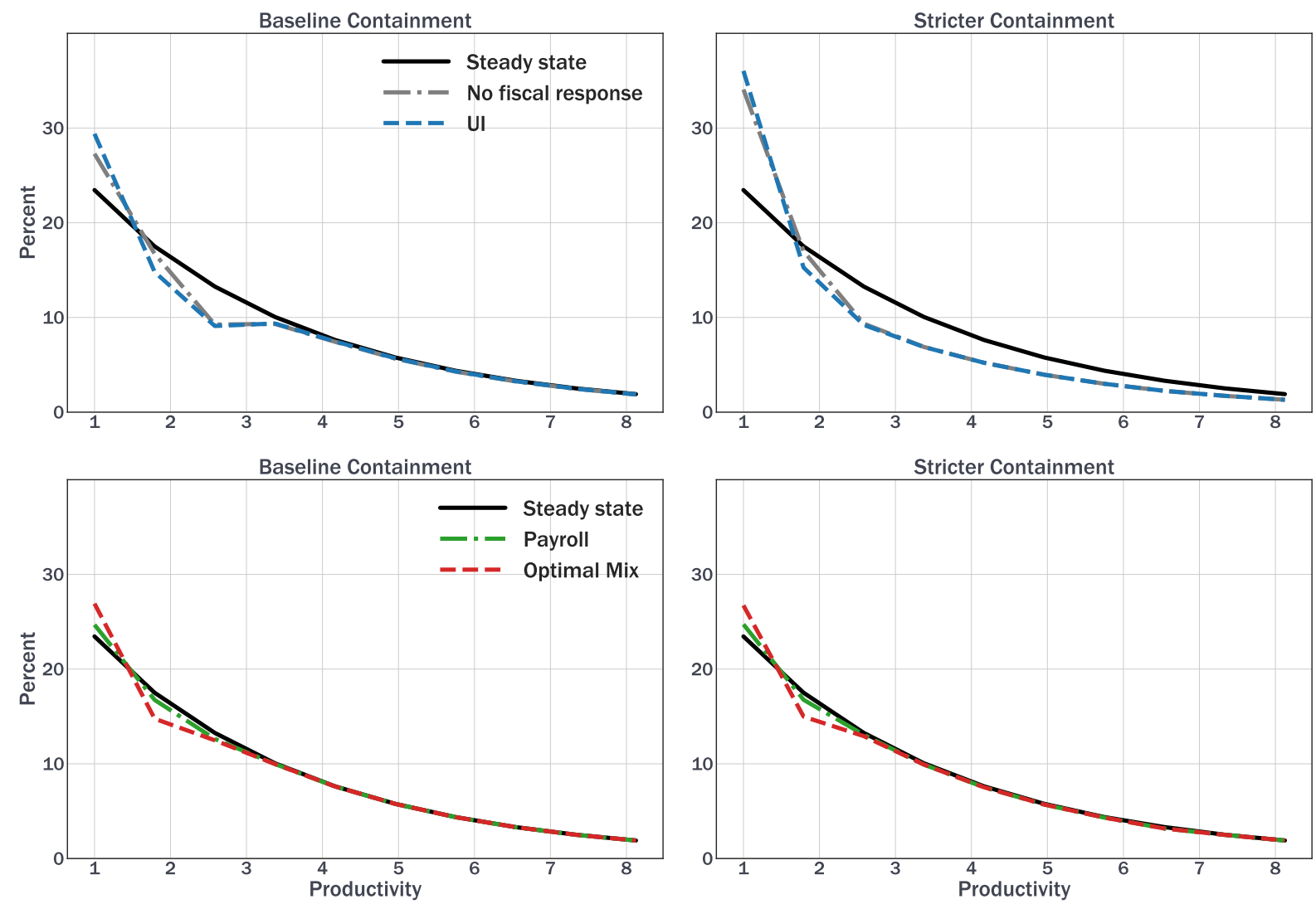

Notes: This figure plots the pre- (steady state) and post-containment (seven weeks after the containment) match-capital distribution. The post-containment distributions are shown separately for the following scenarios: i) no fiscal response, ii) only expanding UI benefits, iii) only introducing payroll subsidies, and iv) implementing the optimal policy mix.

20 percent to $\tau_{q}=0.90$ (i.e., $1.2 \tau_{q}$ ) also increases the budget share of payroll subsidies from 20 percent to 42.1 percent in the optimal policy mix. This implies less-generous UI benefits $b^{*}=1.84$ and twice the payroll subsidy $\tau_{p}^{*}=0.20$. The optimal policy yields a welfare gain of 3.42 percent in additional lifetime consumption. ${ }^{1}$

Figure A1 compares economic outcomes under the two containment measures of varying strength when different labor market policies are implemented. The second column shows that, compared with the lax (baseline) containment, the no-fiscal-response scenario induces a much larger increase in the unemployment rate and a significantly larger drop in ALP and, correspondingly, output. These effects are once again exacerbated by the UI-only policy because strict containment turns even high-productivity matches to low-surplus ones that are now vulnerable to dissolution. The top right panel of Figure A2 shows that under no fiscal response (gray) and UI (blue), even the matches at the top of the productivity distribution are lost. Firms that would have otherwise preserved their relationship with an experienced worker under a lax containment are no longer capable of doing

\footnotetext{
${ }^{1}$ When we consider UI and payroll subsidy policies under stricter containment in isolation, we again find that the payroll subsidies are preferred over the UI extension. Relative to no-fiscal policy, the welfare gain of the former is 3.34 percent and the welfare gain of the latter is 0.24 percent.
} 
so under strict containment. Thus, the optimal policy now prescribes a larger payroll subsidy $\left(\tau_{p}^{*}=0.2\right)$. The bottom right panel of Figure A2 shows that the match quality distribution under the optimal policy (red) approaches the pre-crisis distribution, while a full-payroll subsidy (green) yields only marginal gains. As a result, the optimal policy significantly alleviates the drop in productivity and output even during containment, which is the reason why the welfare gain from the optimal mix becomes much higher under strict containment. Once again, we note that the 40 percent budget allocation to payroll subsidies captures most of the gains that a full budget allocation to payroll would have achieved, as shown in the bottom right panel of Figure A2.

\section{A.6 Earnings Drop upon Job Loss}

To estimate the consequences of job loss for individual earnings, we follow Jacobson et al. (1993) and Stevens (1997) and use a distributed lag regression. We first simulate a weekly panel of workers from the steady-state equilibrium of the model. Next, to compare between the existing empirical estimates and their model counterparts, we aggregate the model's weekly data into an annual frequency. Finally, we run the following regression on model-generated annual data:

$$
y_{i t}=\sum_{k \geq-5}^{20} \psi_{k} D_{i t}^{k}+\alpha_{i}+\epsilon_{i t} .
$$

Here, $y_{i t}$ denotes the labor earnings of individual $i$ in year $t$ and $\alpha_{i}$ captures individual fixed effects. The vector of dummy variables $D_{i t}^{k}$ indicates an individual's job loss in a future, current, or previous year. ${ }^{2}$ For example, $D_{i t}^{5}=1$ if individual $i$ lost a job in year $t-5$ and zero otherwise.

We estimate $\psi_{k}$ for the five years preceding the job loss $(k=-5,-4,-3,-2,-1)$, for the year of the job loss $(k=0)$, and for every year until 20 years after the job loss $(k=1,2, \ldots, 20)$. Here, $\psi_{k}$ captures the effect on the year $t$ earnings of individuals who are displaced $k$ years before/after year $t$ (treatment group). The control group consists of individuals who never experience displacement over the estimation period. Thus, individuals in the control group have $D_{i t}^{k}=0$ for all years $t$. In our results below, the earnings drop upon job loss measures the change in the earnings of the treatment group relative to the change in the earnings of the control group. Finally, we report the estimated earnings losses $\psi_{k}$ as a percent of the mean earnings in the year prior to the job loss.

Figure A3 compares the model's predictions with the empirical estimates obtained by Jarosch (2015). Two main points are worth highlighting.

First, even though the baseline calibration does not target the earnings drop upon job loss, its magnitude (35 percent) in the year following the job loss is remarkably close to the data (37 percent), at least to that measured in Jarosch (2015), who uses administrative data from Germany to estimate a specification similar to Equation (A2). For the U.S., our estimate is smaller than the estimate in Jacobson et al. (1993) (40 percent) and larger than that in Stevens (1997) (30 percent). Moreover, Davis and von Wachter (2011) and Birinci (2020) estimate the earnings drop upon job

\footnotetext{
${ }^{2}$ We obtain yearly earnings by summing weekly earnings. If an individual loses a job for at least one week in a year, then we set the job loss dummy to one for that year.
} 
Figure A3: Earnings dynamics upon job loss: Data vs model

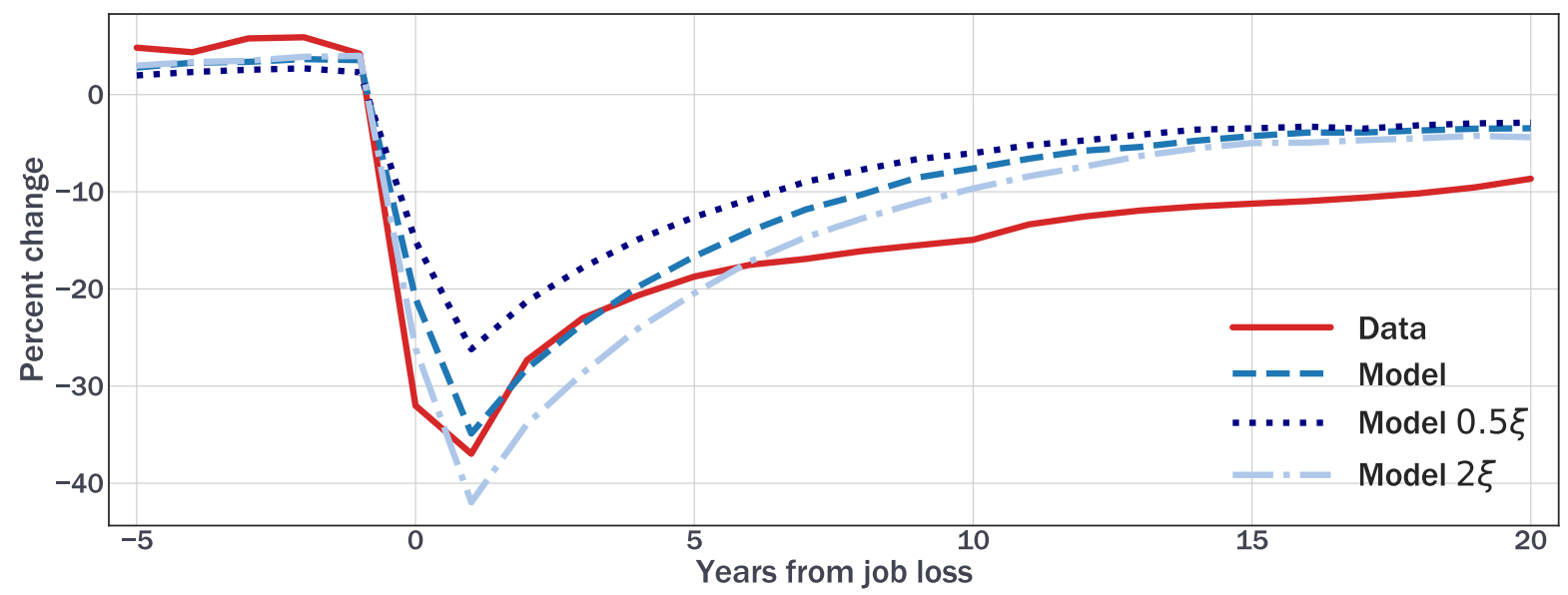

Notes: This figure plots the earnings dynamics upon job loss. The model results are obtained by estimating a distributed lag regression on the annual data that is simulated from the model. The three series correspond to the following cases: i) the baseline calibration (dashed blue line), ii) the economy with the productivity upgrade probability $\xi$ of half the baseline value (dotted blue line), and iii) the economy with $\xi$ twice the baseline value (dash-dotted blue line). The empirical estimates are obtained from Jarosch (2015).

loss separately for recessions and expansions. Using administrative data from the U.S., Davis and von Wachter (2011) find larger earnings losses upon displacement in recessions (39 percent) than in expansions (25 percent). Similarly, using the Panel Study of Income Dynamics, Birinci (2020) finds an earnings drop of 39 percent in recessions and 22 percent in expansions in the year following the job loss. To sum up, our model implies an estimate of the earnings drop upon job loss that is within the range of existing estimates for recessions and expansions. That being said, the longer-term effects are understated by around 5 percentage points compared to the data.

Second, we recognize that while the magnitude and persistence of the earnings drop upon job loss in the model are not too far off the data, these losses in the model are entirely due to matchspecific capital, whereas in the data they may also be driven by losses in other forms of human capital (general, occupation-specific, etc.), employer stigma, and so on. In order to understand how differences in the importance of match-specific capital map to the optimal policy, in Section 4 we conduct a robustness analysis on $\xi$. This parameter is the probability that match productivity increases on the job and therefore controls how important match-specific capital is. We consider two alternative values for this parameter: half $(0.5 \xi)$ and double the baseline $(2 \xi)$ values. Figure A3 shows that as $\xi$ increases, the earnings drop upon job loss becomes more severe, both in the short- and long-term. This result arises because a large $\xi$ implies faster productivity growth for the control group over the period during which job losers remain unemployed. 